Recurso de Amparo en favor de Patricia Troncoso (2008): Corte de Apelaciones de Chillán, 28 enero 2008, Rol No 51-2008 (Recurso de amparo).

Gendarmería contra Troncoso y otros (2007): Corte de Apelaciones de Temuco 4 noviembre 2007, Rol No 1848-2007 (Recurso de protección).

Caso Poluco y Pidenco, Juicio seguido contra José Benicio Huenchunao Mariñan y Otros (2004): Tribunal de Juicio Oral en lo Penal de Angol, RIT No 21-2004 (Juicio oral).

Juico seguido contra Pascual Huentequeo Pichún, Paillalao, Patricia Roxana Troncoso Robles y Segundo Aniceto Norín Catriman (2003): Tribunal de Juicio Oral de Angol, R.I.T. No 2-2003 (Juicio oral).

Juico seguido contra Pascual Huentequeo Pichún, Paillalao, Patricia Roxana Troncoso Robles y Segundo Aniceto Norín Catriman (2003): Corte Suprema, 3 julio 2003, Rol No 1743-03 (Recurso de nulidad).

Condición Jurídica y Derechos Humanos del Niño (2002): Corte Interamericana de Derechos Humanos, 25 agosto 2002, O.C. No 17/2002 (Opinión Consultiva).

Intendente de Santiago en favor de quienes efectúan una huelga de hambre (1997): Corte de Apelaciones de Santiago Rol No 4891-97 (Recurso de protección), en: Gómez, Gastón (2005): Derechos Fundamentales y Recurso de Protección (Santiago, Ediciones Universidad Diego Portales), p. 265, nota 149.

Intendente de la Región de Atacama con el Párroco de El Salvador (1986): Corte de Apelaciones de Copiapó, 3 julio 1986, Rol No 3560-86 (Recurso de protección).

Rozas Vial con Párroco de San Roque (1984): Corte Suprema, 9 agosto 1984, Rol No 167-849 (Recurso de protección), en: Revista Chilena de Derecho, Vol. 12, 1985, pp. 147 a 149.

\title{
Sitios web
}

BASCUÑán, Antonio (2011). "Huelga de Hambre, Alimentación Forzada y Estado de Derecho" (fecha de consulta: 3 de julio de 2011). Disponible en: http:// www.mapuexpress.net/content/ publications/print.php?id=5128.

Corral Talciani, Hernán (2010). "Derecho y Academia” (fecha de consulta: 3 de julio de 2011). Disponible en: http://corraltalciani.wordpress.com.

Comisión Asesora para la Calificación de Detenidos Desaparecidos, Ejecutados Políticos y Víctimas de Prisión Política y Tortura -Comisión Valech(2011). Informe de Prisión Politica y Tortura, disponible en: http://www.indh. $\mathrm{cl}$ /informacion-comision-valech (fecha de consulta 2 julio 2011). 
Comisión de Verdad Histórica y Reconciliación -Comisión Rettig- (1991). Informe de la Comisión Nacional de Verdad y Reconciliación. Derechos Humanos, Gobierno de Chile (fecha de consulta 2 de julio de 2011), disponible en: http://www.ddhh.gov.cl/ddhh_rettig.html.

Obispos del Sur de Chile (2001). "Carta pastoral por la Dignificación del Pueblo Mapuche" (fecha de consulta: 24 junio 2011). Disponible en: www.institutoindigena.cl/images/97014900_1270539796.pdf.

Obispos del Sur de Chile (2002). "Documento de Trabajo: Por un Nuevo Trato con el Pueblo Mapuche" (fecha de consulta: 24 junio 2011). Disponible en: http:/ /www.institutoindigena.cl/ images/93665700_1270539706.pdf.

Sagrada Congregación para la Doctrina de la Fe -S.C.D.F.- (1980). "Declaración «iura et bona» sobre la eutanasia" (fecha de la consulta: 3 septiembre 2012). Disponible en: http://www.vatican.a/roman_curia/congregations/ cfaith/documents/rc_con_cfaith_doc_19800505_euthanasia_sp.html.

Venturelli, J. (2011). "Huelga de hambre en el prisionero de conciencia y tratamientos forzados" (fecha de consulta: 3 julio 2011), disponible en:http:// derechoshumanosy justiciaparatodos.blogspot.com/2011/06/huelga-dehambre-en-el-prisionero-de.html.

43a Asamblea Médica Mundial (1991). "Declaración de Malta de la Asociación Médica Mundial sobre las Personas en Huelga de Hambre" (fecha de consulta: 6 junio 2011). Disponible en: http://www.colegiomedico.cl/ Default. aspx?tabid=238. 
Estudios Constitucionales, Año 11, № 2, 2013, pp. 369 - 424.

ISSN 07180195

Centro de Estudios Constitucionales de Chile Universidad de Talca

"El núcleo laboral del Derecho Constitucional a la libertad de empresa" Pedro Irureta Uriarte

\title{
EL NÚCLEO LABORAL DEL DERECHO CONSTITUCIONAL A LA LIBERTAD DE EMPRESA* \\ The Labor Core of the Constitutional Right \\ TO BusINESS FREEDOM
}

\author{
Pedro Irureta Uriarte** \\ Universidad Alberto Hurtado - Chile \\ piruret@uahurtado.cl
}

RESUMEN: El derecho a desarrollar cualquier actividad económica, consagrado en el artículo 19 No 21 de la Constitución (también conocido como libertad de empresa), contiene una serie de garantías que se vinculan no sólo con el Orden Público Económico sino que además con el denominado Orden Público Laboral. En virtud de dicho precepto se explica parte importante de las facultades del empresario en su calidad de empleador, y su adecuada comprensión exige un análisis sistemático de la libertad de empresa en congruencia con los derechos que la propia Constitución le reconoce al trabajador. El artículo $19 N^{\circ} 21$ no es una garantía aislada ni excluyente del sistema de relaciones laborales que ha diseñado la Constitución, y tampoco puede ser visto como una norma de carácter meramente economicista.

ABSTRACT: The right to develop any economic activity, established in the article $19 N^{\circ} 21$ of the Chilean Constitution (also known as business freedom), contains an array of guarantees linked not only to public economic legal order but also to the so called Public Labor Legal Order. By virtue of this precept most of the businessman faculties as an employer, and the appropriate understanding of

\footnotetext{
* Abreviaturas: AL (Actualidad Laboral); AS (Agricultura y Sociedad); AUH (Anales de la Universidad Hispalense); BEE (Boletín de Estudios Económicos); CEJ (Cuadernos de Extensión Jurídica); CPR (Constitución Política de la República); DA (Documentación Administrativa); DFL (Decreto con Fuerza de Ley); DO (Diario Oficial); EL (Estudios Laborales); GJ (Gaceta Jurídica); HP (Hacienda Pública); IEP (Ius et Praxis); PJ (Poder Judicial); RAP (Revista de Administración Pública); RCEC (Revista del Centro de Estudios Constitucionales); RCHD (Revista Chilena de Derecho); RDJ (Revista de Derecho y Jurisprudencia y Gaceta de los Tribunales); RDM (Revista de Derecho Mercantil); RDPR (Revista de Derecho Privado); RDDPUCV (Revista de Derecho de la Pontificia Universidad Católica de Chile); REDC (Revista Española de Derecho Constitucional); REDT (Revista Española de Derecho del Trabajo); REC (Revista Estudios Constitucionales); REICE (Revista de Estudios e Investigación de las Comunidades Europeas); RFDUM (Revista de la Facultad de Derecho de la Universidad de Madrid); RFM (Revista Fallos del Mes); RGD (Revista General de Derecho); RIT (Revista Internacional del Trabajo); RJCEE (Revista Jurídica de la CEE y de la Competencia); RL (Relaciones Laborales); RPS (Revista de Política Social); TS (Tribuna Social). Trabajo recibido el 9 de enero de 2013 y aprobado el 24 de julio de 2013.

** Licenciado en Derecho por la Pontificia Universidad Católica de Chile, y Doctor en Derecho por la Universidad Complutense de Madrid, Profesor de Derecho del Trabajo y de Introducción al Derecho de la Universidad Alberto Hurtado.
} 
this precept, demand a systematic analysis of business freedom in congruence with the rights that the Constitution recognizes to workers. The article $19 N^{\circ} 21$ is neither an isolated guarantee nor excludes the working relationships system designed in the Constitution, and it cannot be seen either as a merely economic norm.

Palabras clave: Derecho Constitucional a la Libertad de Empresa, Derechos Fundamentales en la Relación Laboral, Constitución, Orden Público Laboral.

Key words: Constitutional right to Business Freedom, Fundamental Rights in Working Relationships, Constitution, Public Labor Legal Order.

\section{INTRODUCCIÓN}

Los textos constitucionales, incluido el chileno, se circunscriben a asegurarle al individuo un conjunto de derechos básicos de orden económico-social, y entre los cuales destacan el desarrollo libre de cualquier actividad empresarial, así como la posibilidad de competir en plano de igualdad con otros agentes económicos ${ }^{1}$. De esta manera, la Constitución traza sobre la organización productiva $-y$, también, sobre la figura del empresario- las características básicas de funcionamiento dentro de un orden determinado, arrastrando tras de sí una serie de regulaciones, de carácter mercantil, tributario o laboral, haciendo congruente sus planteamientos con las normas básicas señaladas en la Carta Fundamental2 ${ }^{2}$.

La Constitución ha reconocido este tipo de garantías como un derecho fundamental (art. 19 No 21 CPR). Aun cuando no establece una definición directa de la figura del empresario, ni tampoco de la empresa, la norma del artículo 19 No 21 CPR sí plantea las directrices necesarias para su configuración, regulando de paso el fundamento jurídico constitucional de la actividad empresarial de los individuos ${ }^{3}$. Por cierto, no se trata de una norma aislada, sino que la misma se incrustó en un abanico normativo que explícitamente buscaba irradiar las grandes bases del Orden Público Económico (y en las cuales destacaba, también, el derecho de propiedad, la libre adquisición de bienes, la no discriminación que deben dar el

\footnotetext{
1 Esta clase de garantías también son reconocidas, en otros ordenamientos, bajo el concepto de libertad de empresa. Esta última expresión resulta más amplia que la de libre iniciativa económica, ya que comprendería la libertad de ejercer una actividad económica en sentido estricto, pero también la libertad contractual y la libertad de competencia (vid. CiDONCHA [2006], p. 47). Sin perjuicio de lo anterior, en el presente texto se utilizarán de manera indistinta ambos términos.

2 Cfr. Montoya (1994), p. 199.

3 Sobre los antecedentes históricos de esta garantía, vid. por todos NAVARRO (1999), p. 185 y NavARro (2001), pp. 299 y ss.
} 
Estado y sus organismos en materia económica y la igualdad ante la ley) ${ }^{4}$. Dentro de ese objetivo, se pretendía robustecer la libertad económica de los individuos como una expresión de la autonomía personal, así como circunscribir la intervención del Estado a un ámbito meramente subsidiario en el entendido de que la facultad de los particulares para emprender actividades productivas constituye un "derecho que el Estado no puede ni debe eliminar"5. Desde esta perspectiva, la Carta de 1980 no podría ser catalogada como un instrumento ambiguo o neutral toda vez que representaba una clara definición del Orden Público Económico, pretendiéndose de este modo que toda su concepción preceptiva inspire la legislación que ejecute sus mandatos ${ }^{6}$. En este contexto, el constituyente, más que juridificar un determinado modelo, lo que hizo fue establecer los distintos elementos que disciplinan la actividad económica de la comunidad, diseñando el marco jurídico unitario en el que pueden desenvolverse todos los agentes económicos, tanto públicos como privados ${ }^{7}$.

Este Orden Público Económico ha eclipsado, tradicionalmente, el componente laboral que emana de sus normas. Más aún, el diseño económico que traza la Constitución no puede entenderse sin aceptar la existencia de otro Orden Público, ahora propiamente laboral, que justifica los poderes del empresario (en cuanto empleador), y que dibuja una serie de deberes para ambas partes del contrato de trabajo. Ciertamente, las regulaciones más destacadas del Orden Público Laboral se encuentran en los artículos 19 No 16 y 19 CPR; pero ello no puede ocultar que bajo el reconocimiento de la libertad de empresa se termina juridificando un conjunto de derechos íntimamente vinculados a la actividad laboral del empresario y que permiten configurarlo como un titular de facultades de dirección, organización y disciplina.

${ }^{4}$ Cfr. opinión de Díez, Sergio y Silva Bascuñán, Alejandro, en Actas Oficiales de la Comisión de Estudios de la Nueva Constitución, sesión No 68, pp. 16 y 17. Vid. también, el planteamiento de Romo, Alicia en sesión No 388, p. 2907.

5 Cfr. Bertelsen (1987), p. 120. Vid. también Irarrázaval (1987), p. 100 y Guerrero (1979), pp. 80 y s.

${ }^{6}$ Cfr. BAsSa; Viera (2012), p. 663.

7 Con todo, hay que tener presente que la afirmación sobre una eventual falta de "neutralidad" por parte del texto constitucional chileno puede provocar más de algún equívoco, en el sentido de que el reconocimiento de la libertad empresarial no puede ser confundido con la consagración de un determinado sistema económico. Por lo demás, en general no existen en el orden constitucional comparado adhesiones explícitas a un sistema económico determinado (cfr. AlberTi (1993), p. 45. Vid. también, y entre otros, IrURETA (2000), p. 105; Benda et al. (1996), pp. 561, 562 y 563; CidOnCHA (2006), p. 77; DOnges (1977), pp. 133 y 134, y Montalvo (1985), p. 242). 
En este contexto, el sistema de relaciones laborales puede explicarse -en clave constitucional- mediante un delicado equilibrio entre el denominado Orden Público Laboral y el Orden Público Económico. Pero más que concebirlos como órdenes contrapuestos, lo cierto es que muchos de los derechos y obligaciones de ambas partes de la relación laboral se explican recurriendo a figuras de uno u otro orden. Ello ocurre precisamente con el empresario -en cuanto empleador-, pues gran parte del respaldo normativo de sus facultades (así como sus obligaciones) emana precisamente del contenido esencial de la libertad de empresa.

En el presente artículo se busca acreditar que el contenido esencial del artículo 19 No 21 CPR explica ciertas y determinadas atribuciones que le corresponden al empresario en su calidad de empleador. Esas atribuciones deben ejercerse dentro de un delicado equilibrio entre Orden Público Laboral y Orden Público Económico, de forma tal que la configuración constitucional de la empresa y del empresario exige un análisis armónico y sistemático de la Carta Fundamental. Con todo, y aun cuando el análisis de la garantía se efectúa desde una perspectiva esencialmente dogmática, de todas formas en determinados casos se ha hecho referencia a fuentes jurisprudenciales que permiten confrontar o respaldar algunas de las argumentaciones planteadas.

\section{Contenido ESENCIAL DE LA LIBERTAD PARA DESARROLLAR CUALQUIER ACTIVIDAD ECONÓMICA}

Para determinar la esencia de un derecho resulta preciso delimitar con claridad sus contornos y descubrir los atributos que subyacen en la consagración constitucional del mismo. Este ejercicio es aún más relevante si se considera que el derecho en cuestión se encuentra establecido de manera general, sin que el texto que da cuenta de la garantía haya dado mayores elementos sobre los rasgos cualitativos de la misma. Ello ocurre precisamente con la norma del artículo 19 No 21 CPR, ya que en este caso el Código Político se limita a reconocer la libertad para desarrollar cualquier actividad económica sin agregar otros elementos normativos que permitiesen clarificar su contenido esencial. De cierta manera, el texto presupone un conocimiento previo de la libertad económica, relegando su accionar al mero establecimiento de límites fundados en bienes jurídicos indeterminados o en la capacidad regulatoria del legislador.

A lo anterior habría que agregar que la norma del artículo 19 No 21 CPR no sólo podría ser catalogada como una garantía de contenido eminentemente complejo, sino que además su incorporación dentro del Código constitucional obliga a desentrañarla de manera unitaria y sistemática en relación con el catá- 
logo de derechos fundamentales ${ }^{8}$. En efecto, el artículo 19 No 21 CPR no es un precepto aislado dentro de la Carta Fundamental; no sólo convive con otras normas de carácter económico-social, sino que, además, presupone la existencia de un conjunto de disposiciones que la complementan y configuran. Algunas de ellas se encuentran expresamente reconocidas en la Constitución; otras, en cambio, se deducen del contexto general que presenta el texto constitucional ${ }^{9}$. En este esquema, cobran especial relevancia las normas de carácter social y laboral, que le imprimen a la libertad de empresa un sentido determinado, acorde con las exigencias que rigen la vida de los demás integrantes de la sociedad ${ }^{10}$.

En el caso chileno, el artículo 19 No 26 CPR establece la posibilidad de una acción intermedia de los poderes públicos, reflejada en una norma de rango legal. Su significado último, por tanto, no es otro que el de asegurar que la regulación de los ámbitos de libertad se lleve a efecto exclusivamente de la voluntad de un legislador, razón por la cual tales ámbitos quedarán exentos de la acción directa de la autoridad administrativa ${ }^{11}$. Nótese, en todo caso, que la Constitución no es que exija perentoriamente la existencia de la ley, sino que sencillamente se coloca en la hipótesis de que ello ocurra.

Lo anterior tiene especial relevancia en el caso de la libertad de empresa. El mismo inciso primero del artículo 19 No 21 CPR parte de la hipótesis que el derecho a desarrollar cualquier actividad económica debe ejercerse "respetando las normas legales que la regulen". Por tanto, la Constitución prefigura un derecho, no de manera absoluta, a fin de que su ejercicio sea compatible con otros bienes jurídicos expresados en un determinado marco regulatorio ${ }^{12}$. Y dentro de ese

\footnotetext{
8 Sobre la necesidad de que los derechos constitucionales no sean considerados de manera aislada o independiente, vid. sentencia del Tribunal Constitucional, Rol No 1273-2010, de 20 de abril de 2010 (considerando $47^{\circ}$ ).

9 Sobre el análisis complementario de este tipo de normas en los textos constitucionales, vid. MARTín-RETORTILLO BAQUer (1988), p. 153.

10 Cfr. en este sentido, y entre otros, los artículos 19 No 9, 19 No 16, 19 No 18 y 19 No 19 de la Constitución.

11 Vid. en este sentido sentencia del Tribunal Constitucional, Rol No 167-1993, de 6 de abril de 1993; sentencia del Tribunal Constitucional, 185-1994, de 28 de febrero de 1994, y sentencia de la Corte Suprema, Rol No 563-2006, de 21 de junio de 2007. En el plano doctrinal vid., además, Fermandois VöHrINGER (2001), p. 121. Con todo, parte de la doctrina ha matizado este criterio al señalar que sólo la regulación general del derecho se encuentra sujeto a reserva de ley, debiendo mantenerse en normas de rango legal los elementos esenciales del régimen que limita la libertad de empresa en un determinado ámbito de actividad (vid. Paz-Ares; Alfaro (2008), pp. 982 y 983).

12 Cfr. Cea (1991), p. 24.
} 
marco regulatorio cabe aplicar, evidentemente, el orden público laboral expresado esencialmente en los preceptos contenidos en el Código del Trabajo y en las leyes laborales que para estos efectos adquieren carácter de irrenunciables mientras subsista el contrato de trabajo (art. $\left.5^{\circ} \mathrm{CT}\right)^{13}$. Dicho de otra manera, el ejercicio de la libertad de empresa presupone conciliar este derecho fundamental con un marco regulatorio de muy distinto orden y dentro del cual destacan las normas que impregnan el denominado Orden Público Laboral.

Lo que ocurre, en definitiva, es que el ejercicio de la libertad económica debe ajustarse a una regulación compatible con las diversas necesidades y derechos que existen en el orden social. De este modo, la exacta configuración de la libertad permite armonizar su ejercicio con aquellos límites que se derivan de la existencia de comunidades organizadas políticamente -el caso del Estado- y con los intereses generales que emanan del desenvolvimiento natural que tiene la sociedad ${ }^{14}$. Por ello, no debe extrañar que conjuntamente con la existencia de una libertad económica amplia -que le permite al individuo desarrollar cualquier iniciativa de esta índole-, el Código Político de 1980 haya fijado, también, otros derechos que deben armonizarse con el núcleo del artículo 19 № 21. No hay que olvidar que la libertad económica convive con otros derechos y libertades dentro del texto constitucional, razón por la cual el establecimiento de límites tiene su lógica y justificación en el ejercicio de esos otros derechos que ejercen los demás individuos en el entorno social.

Aceptando una congruencia entre ejercicio del derecho y adecuada regulación, tenemos que concluir que no hay actividad industrial, comercial o de servicios que no se encuentre sujeta a un marco regulador y a una intervención o control, mayor o menor, por parte de la Administración o del ordenamiento jurídico en general ${ }^{15}$. Resulta que en el mundo contemporáneo, con la excesiva división de la actividad productiva, los derechos económicos deben ser entendidos, con pa-

13 Sobre el fundamento constitucional de la irrenunciabilidad de los derechos laborales, vid. por todos IRURETA (2006), pp. 61 y ss.

14 Cfr. por todos, Álvarez (1992), p. 398, y García (1993), p. 998. En el ámbito nacional, vid. Dougnac (1986), pp. 6 y ss.

15 Cfr. AriÑo (1995), p. 99, y ToRres (1992), p. 565. Por lo demás, siempre han existido en el ejercicio de las actividades económicas límites de diversa naturaleza, ya sean externos, convencionales o legales, y que se traducen en pactos de no competencia, en la constitución de monopolios o en la nacionalización de algunos sectores. A mayor abundamiento, cfr. FernÁndez (1991), pp. 407 y 412; Font (1987), p. 113, y GarCía (2008), pp. 46 y ss. 
labras de Ossenbuhl16, en un contexto de relación. Sus decisiones, sus normas, sus prohibiciones, terminan afectando no sólo a los trabajadores que laboran en una empresa, sino que a una gran cantidad de usuarios y consumidores, que demandan bienes y servicios y condiciones ambientales acordes con la calidad de vida que desea la sociedad actual ${ }^{17}$. El empresario de hoy ya no es considerado como un individuo abstracto y aislado, sino como miembro de una sociedad en la cual se plantean exigencias más allá de la mera producción de bienes y servicios.

En razón de esto, la garantía del artículo 19 No 21 CPR debe ser compatibilizada con la normativa legal que regula cada actividad, y con los demás derechos constitucionalmente reconocidos ${ }^{18}$. De esta forma, habrá que buscar un equilibrio entre libertad y regulación, o entre aquélla y las exigencias generales derivadas de la moral, el orden público o la seguridad nacional; pues resulta que una interpretación armónica de la Constitución haría imposible aceptar la anulación de un principio por el otro ${ }^{19}$.

La necesaria exigencia de compatibilidad lleva a sostener que la libertad económica no implica, por parte de la Administración, un desentenderse de la actividad empresarial; sino que, por el contrario, subsisten las inspecciones a las empresas, las peticiones de datos, la exigencia de determinadas características técnicas y de volumen mínimo de producción, así como el cumplimiento de una serie de otros requisitos para el desempeño de una actividad económica. Todas esas exigencias permiten regular la libertad sin sobrepasar la frontera que impone su contenido esencial ${ }^{20}$.

El hecho que la libertad de empresa se estructure como un derecho fundamental ${ }^{21}$ implica que el ordenamiento jurídico le reconoce al titular la capacidad para exigir ante los órganos jurisdiccionales el cumplimiento de la obligación insatisfecha ${ }^{22}$. Por tanto, su protección hay que situarla dentro del ámbito de competencia de los Tribunales de Justicia, toda vez que el titular de este derecho ostenta un status jurídicamente protegible de acuerdo con lo establecido en la pro-

\footnotetext{
16 Vid. Ossenbuhl (1991), p. 16.

17 Cfr. Cidoncha (2006), p. 254.

18 Cfr. por todos, Alborch (1980), p. 165; y Torres (1992), p. 563.

19 Cfr. Montoya (1980), p. 295.

20 Cfr. Nogueira (1997), pp. 181 y ss.

21 Vid. por todos Gallego (1994), pp. 248 y 251. Vid. también Cea (1991), pp. 21 y ss.

22 Cfr. Prieto (1984b), p. 436.
} 
pia Constitución. Y dicha protección "abarca todos los aspectos de o dimensiones de la actividad empresarial" 23 . De esta manera, el reconocimiento constitucional de la libertad de empresa termina vinculando a todos los poderes públicos, en especial a todos los Jueces y Tribunales ${ }^{24}$; su contenido se encuentra garantizado bajo la tutela efectiva de dichos Jueces y Tribunales; y su ejercicio sólo podrá ser regulado por una ley formal -que en todo caso respetará su contenido esencial-, sin perjuicio del uso secundario o residual de normas reglamentarias de ejecución y desarrollo en la ordenación de la actividad empresarial ${ }^{25}$.

La libertad de empresa, como se ha dicho hasta ahora, viene constituida como un derecho fundamental modalizado por las exigencias generales que impone la propia Constitución y el ordenamiento jurídico en general. De ese modo, el ejercicio de la libertad se ve acompañado de una serie de cargas, deberes y vinculaciones que obligan a modalizar su configuración ${ }^{26}$. Las exigencias de la moral, la seguridad nacional y el orden público, así como las propias normas reguladoras de la actividad, estructuran esta libertad y permiten complementar el interés individual con el interés colectivo ${ }^{27}$.

Por su parte, el artículo 19 No 26 CPR permite que por ley se pueda regular el ejercicio de esta libertad, pero respetando siempre en dicha regulación su contenido esencial. Esta exigencia constituye un límite evidente para el legislador; pero al mismo tiempo reconoce la posibilidad cierta de que la libertad empresarial exista previamente y que, en consecuencia, pueda ser objeto de concreción. Dicha concreción obliga al legislador a conformar obligatoriamente la norma con aquella parte del derecho o libertad que resulta necesaria para que el ordenamiento jurídico permita a su titular la satisfacción, dentro de su tipo o peculiaridad, de aquellos intereses para cuyo establecimiento el derecho se otorga.

Por ello, cuando la Constitución señala que los preceptos legales que regulen, complementen o limiten la garantía "no podrán afectar el derecho en su esencia,

23 Vid. Paz-Ares; Alfaro (2008), p. 982.

24 Cfr. entre otros muchos, Barnes (1988), p. 208; Del Valle (1993), pp. 186 y 187; Menéndez (1985), p. 59; Montoya (1995), pp. 33 y ss. y 47; Montoya (1980), p. 274; Prieto (1984a), p. 453, y Serrano (1979), p. 457.

25 Cfr. entre otros, Gallego (1994), p. 250; Nogueira (1997), pp. 282 y ss.; Prieto (1984a), p. 477, y Rubio (1996), pp. 431 y ss. Lo que no podría hacer la autoridad, en todo caso, es imponer condiciones no previstas en la ley (cfr. sentencia de la CORTE SUPREMA, Rol No 17.660, de 9 de julio de 1991), ya que la potestad reglamentaria se apoya en cláusulas legales de carácter general.

26 Cfr. De Отто (1991), p. 169.

27 Cfr. Cea (1991), pp. 18 y ss. 
ni imponer condiciones, tributos o requisitos que impidan" el libre ejercicio de las libertades empresariales, no está haciendo más que recalcar la imposibilidad de que la acción del legislador termine menoscabando, perjudicando o influyendo desfavorablemente, en el núcleo de la libertad. De ahí la importancia de interpretar el artículo 19 No 26 CPR como una imposibilidad de afectar la libertad de modo que ésta se haga impracticable o engorrosa en su ejercicio, dificultándola más allá de lo razonable ${ }^{28}$.

Determinar el contenido de la libertad económica o de empresa, ciertamente no es fácil. No sólo porque el texto constitucional omite un pronunciamiento expreso al respecto, sino también por la indeterminación jurídica de muchos de los términos a que hace referencia la propia norma constitucional. A ello habría que sumar la compatibilidad que debe existir entre libertad de empresa y las exigencias derivadas de la regulación, de los bienes jurídicos indeterminados a los cuales hace referencia la Constitución y de todo el ordenamiento jurídico en general. Todos esos elementos obligan a examinar detalladamente la esencia de esta libertad dentro de un contexto de interpretación unitario y sistemático de la Constitución, de modo tal que cualquier conducta subsumible dentro de la definición abstracta pueda ser ejecutada sin dificultades. Por ello, más que pretender una construcción genérica de este contenido lo más conveniente pareciera ser ir dilucidando situaciones específicas; teniendo en todo caso presente que lo esencial es lo ineludiblemente necesario para poder ejercer el derecho dentro de su tipo o peculiaridad.

Un rasgo evidente en la configuración jurídica de la libertad económica viene dado por la posibilidad que se les reconoce a los individuos para iniciar, sostener o abandonar actividades empresariales lícitas. Es ahí donde radica el rasgo distintivo de este derecho fundamental y donde es posible situar el minimum que subyace en

\footnotetext{
28 Esta tesis debe ser relacionada, también, con la llamada teoría absoluta, en cuya virtud el contenido esencial del derecho es un núcleo duro, absolutamente resistente a la acción limitativa del legislador: "(...) se dice que en el interior del núcleo se dibuja un círculo concéntrico cuya circunferencia es la frontera que el legislador no puede traspasar en ningún caso, ni siquiera cuando el límite pudiera venir justificado por la protección de otro derecho o de otro bien de rango constitucional". Vid. Dе Отто (1991), pp. 131 у 132. Vid. también la sentencia del Tribunal Constitucional, Rol No 976, de 26 de junio de 2008. Con todo, conviene precisar que no es motivo de este artículo la conocida discusión entre teorías absolutas o relativas que se enfrentan para resolver la problemática de los límites materiales en la configuración del contenido esencial de la libertad económica. Ciertamente, hay posturas que reconducen la delimitación del contenido esencial hacia un examen de razonabilidad y proporcionalidad. Desde esta perspectiva (relativa), el contenido esencial es determinado en razón de un control de proporcionalidad de las normas reguladoras del derecho.
} 
él ${ }^{29}$; ya que de ahí se derivan una serie de prerrogativas muy propias del ejercicio de la actividad empresarial como es el caso de la ejecución de potestades directivas, la libre circulación de bienes o la libertad de establecimiento, entre otros factores. Todo atentado significativo contra la iniciativa de ingreso y abandono al mercado supondría afectar gravemente el núcleo esencial del artículo 19 No 21, toda vez que la libertad de ingreso y salida es un presupuesto de la libertad ${ }^{30}$. Por cierto que el acceso o el abandono pueden estar encuadrados dentro de una serie de formalidades que obligan a que la actividad se realice de una determinada forma; pero eso en modo alguno puede alterar el contenido esencial ${ }^{31}$.

La libertad económica no supone que el individuo pueda ejecutar cualquier empresa, sino sólo el de iniciar y sostener en libertad la actividad empresarial. Por ello es importante recalcar que el artículo 19 No 21 consagra un derecho de libertad, pero esa libertad no puede hacerse extensiva a cualquier actividad negocial ya que la propia Constitución se encarga de establecer límites materiales al ejercicio de la misma: siempre y cuando "no sea contraria a la moral, al orden público o a la seguridad nacional, respetando las normas legales que la regulen"32. Esos límites reconducen a la licitud de la actividad. Salvados los límites que impone la Carta Fundamental, la reafirmación de la libertad se reflejará en la capacidad que adquiere toda persona -natural o jurídica- para participar activamente y según su propia iniciativa dentro del sistema económico, bajo las formas y modalidades que estime convenientes ${ }^{33}$.

En ese contexto, el sujeto podrá indagar, previo respeto al ordenamiento jurídico, en actividades tradicionales, atípicas o inusuales, de manera tal que no se

29 Cfr. entre otros muchos Aragón (2005), pp. 23 y ss.; De Gispert (1989), p. 44; De JuAn (1984), p. 161; AriÑo (1995), p. 85, y Freixes (1988), pp. 537 y 538.

30 Cfr. Cidoncha (2006), p. 145.

31 Cfr. Martín-Retortillo (1988), p. 166.

32 Sobre la existencia de limitaciones ordinarias y extraordinarias al ejercicio de los derechos, vid. por todos Nogueira (2005), pp. 15 y ss.

33 La invocación de bienes jurídicos indeterminados, como límite al ejercicio de una libertad, también se encuentra en Constituciones comparadas. Ese es el caso de los artículos $3^{\circ}$ y 41 de la Constitución italiana, en que el ejercicio del derecho a la libre iniciativa económica privada tiene como límites necesarios la utilidad social; la seguridad; la libertad, y la dignidad humana (sobre el particular, vid. por todos CRISAFulLi (1990), p. 289). Consideraciones similares podrían formularse con respecto al artículo 61 de la Constitución portuguesa, del año 1976, que en su inciso primero dispuso que: "La iniciativa económica privada se ejercerá libremente dentro del ámbito definido por la Constitución y por la ley, y teniendo en cuenta el interés general" (cfr. MiRANDA (1993), pp. 447 y ss.). 
le restrinja su capacidad innovadora dentro de cualquier mercado económico ${ }^{34}$. Nótese que cuando se reconoce esta libertad, más que pensar en una organización específica, la Constitución está intentando delimitar la autonomía del empresario $^{35}$, en el entendido de que es él quien pone en movimiento una serie de elementos cuya organización genera el nacimiento de una entidad económica. Y en esta delimitación, el diseño constitucional de la libertad de empresa no hace más que vincularse con el principio de autodeterminación y de autorrealización del individuo ${ }^{36}$.

En razón de lo anterior, el reconocimiento de la libertad de empresa o económica trae implícito la idea de un titular que organiza y dirige los diversos factores que intervienen en el proceso productivo, y que sin su concurso sería imposible diseñar un determinado modelo empresarial de carácter libre. El respeto al contenido esencial, por tanto, supondrá evitar cualquier atentado que impida al titular ejercer los actos constitutivos de la libertad y que se reflejan en una participación activa dentro de la organización productiva ${ }^{37}$.

Por ello, no cabe duda que en el caso del artículo 19 No 21 CPR, el contenido esencial se traducirá en el necesario reconocimiento de todo empresario para ordenar y organizar la actividad productiva, decidiendo los objetivos y planificaciones de acuerdo a los recursos con que se dispone y las necesidades del mercado. Nadie podrá pretender negarle al sujeto su libertad para llevar a cabo este tipo de iniciativas, en el entendido de que ellas le suponen el reconocimiento de una determinada titularidad empresarial ${ }^{38}$. Esa titularidad se refleja precisamente en la posibilidad de ingresar dentro de un determinado mercado económico, ordenar los factores intervinientes y ejercer de manera efectiva el poder de dirección laboral, sin lo cual sería imposible configurar una verdadera actividad empresarial libre.

Asimismo, el contenido esencial del artículo 19 No 21 CPR se distinguirá por una amplitud de recursos, servicios y sectores de la actividad económica en todos los niveles de ésta (primario, secundario y terciario) que queden a disposición de

34 Cfr. Vivanco (2006), p. 444.

35 Cfr. Martínez (1985), p. 3171.

36 Vid. Paz-Ares; Alfaro (2008), p. 981, y García (2008), p. 33.

37 Cfr. BENDA et al. (1996), p. 568.

38 Vid. Martín-Retortillo (1988), p. 168: "En definitiva, la quintaesencia última del derecho a la libertad de empresa, en síntesis, no es sino la posibilidad de su titular -el empresario- de constituir la empresa y de decidir sobre las distintas opciones relacionadas con la actividad económica que desempeña”. 
la libre iniciativa individual dentro de un régimen de libre competencia ${ }^{39}$. Por cierto, ello no se contrapone a la restricción legal de ciertas libertades económicas parciales, como serían la autonomía de inversión, de precios, publicidad o contratación; pero en todos esos casos deberá permanecer un núcleo indisimulable de facultades que no impidan el desarrollo de la actividad.

Lo expuesto trae como consecuencia una amplia libertad de la persona para elegir la actividad económica lícita que pretenda realizar, ejecutarla y desarrollarla de acuerdo a las normas legales que la regulan, obtener los beneficios que de ella se derivan, y extinguir el desarrollo individual de la actividad si así lo estima conveniente. Nadie podría obligar a un sujeto a iniciar o continuar un negocio determinado ${ }^{40}$, salvo, por cierto, en aquellos casos en que la ley exige la liquidación de bienes a objeto de dar cumplimiento forzado a las diversas obligaciones que se derivan de una actividad económica.

En síntesis, deben entenderse incluidos dentro del contenido esencial del artículo 19 No 21 CPR, el libre acceso al mercado, la libre gestión empresarial, así como la libertad de crear y organizar la actividad productiva ${ }^{41}$; debiendo tenerse presente en todos estos supuestos las exigencias derivadas de la moral, el orden público, la seguridad nacional y las normas legales que regulan la actividad.

Por ello, la libertad de empresa debe ser configurada como un derecho fundamental en que permanece como núcleo esencial una libertad de iniciativa económica privada y una autonomía negocial ${ }^{142}$, cuestiones ambas que le permiten al sujeto organizar los diversos medios y factores que intervienen en los procesos productivos ejerciendo las facultades respectivas. Ese núcleo esencial permitiría distinguir una actividad empresarial libre, en que el titular organiza los diversos medios a objeto de obtener un resultado determinado, pudiendo tomar decisiones coordinadas relativas a la producción, inversión, distribución y consumo de

39 Cfr. Font (1979), pp. 232 y ss.; Martínez (1983), pp. 665 y 666; y Martínez (1985), p. 3186. En relación con diversas hipótesis de afectación de la libertad de empresa, cfr. MarTín-Retortillo (1988), pp. 166 a 171, y De JuAn (1984), pp. 160 y ss. A juicio de este último autor, la libertad de empresa admite toda clase de límites, programas y controles que afecten el desarrollo de la actividad empresarial, pero dejando siempre a salvo la libertad de inversión. Y agrega en p. 161, nota 54: "no toda limitación contra la libertad de inversión debe considerarse inconstitucional".

40 Cfr. por todas sentencia de la Corte de Apelaciones de Santiago, Rol No 4.013-95, de 25 de mayo de 1996.

41 Cfr. Montoya (1995), p. 48; y Rey (1994), p. 328. Vid., también, Benda et al. (1996), p. 582.

42 Cfr. Aragón (2005), pp. 23 y ss. 
los bienes ${ }^{43}$. Asimismo, el ejercicio de estas atribuciones dejará al descubierto la actuación de un titular jurídico que ejerce los poderes propios de ordenación empresarial, y cuya negación desdibujaría la idea básica de la libertad económica.

En todo caso, hay que tener presente que cada uno de los derechos dimanantes de la libertad empresarial debe concurrir, en mayor o menor intensidad, a objeto de que la libertad se desarrolle plenamente. No bastaría, en esa lógica, el mantenimiento de algunos atributos y la negación absoluta de otros sin que exista una justificación adecuada. Por ello, la comprensión general de la libertad económica, y en especial su contenido esencial, requieren un análisis sistemático de todos sus atributos al objeto de determinar cabalmente el alcance de la regulación legal.

\section{Derechos QUe INTEgRAN LA LIBERTAD ECONÓMICA}

La libertad para desarrollar cualquier actividad económica (art. 19 No 21 $\mathrm{CPR}$ ) se deriva de la consagración general de la libertad como figura gravitante de todo el entramado constitucional, que le otorga a la persona una capacidad cierta y suficiente para desenvolverse dentro de los parámetros generales que el propio Código Político ha consagrado. Dicho realce de la libertad ya viene instaurado en el artículo $1^{\circ}$ de la Constitución al señalar que las personas nacen libres e iguales en dignidad y derechos. A ello habría que adicionar las referencias de los siguientes incisos del artículo primero, en el sentido que se reconoce la autonomía de los cuerpos intermedios, así como el deber del Estado en orden a contribuir a crear las condiciones sociales que permitan a todos y a cada uno de los integrantes de la comunidad nacional su mayor realización espiritual y material posible. Más aún, el artículo $5^{\circ} \mathrm{CPR}$ eleva los derechos esenciales de la persona humana a la cúspide del ordenamiento jurídico, siendo deber del Estado respetar y promover dichos derechos, tanto los garantizados por la Constitución como por los tratados internacionales ratificados por Chile. Por tanto, la libertad, la autonomía y la dignidad se alzan como el fundamento del orden político y la paz social. Este sólo requerimiento bastaría, en verdad, para fundamentar la existencia de un principio de iniciativa privada en la actividad económica.

De este planteamiento preliminar y básico se deducen, a lo menos, tres consecuencias inmediatas para la libertad económica. En primer lugar, el carácter restrictivo de todas las medidas limitativas de la libertad. En segundo término, la exigencia de que las restricciones sean proporcionales a los fines que se pretende

43 Cfr. Benda et al. (1996), p. 564. 
alcanzar. Y, por último, el sometimiento general de cualquier limitación al principio de igualdad ${ }^{44}$.

La consagración explícita de la libertad de empresa permite clarificar los contornos de la garantía, así como los derechos que emanan de la misma. Si se hubiese optado por una declaración genérica de la autonomía personal, probablemente el proceso interpretativo de la misma habría generado dificultades en torno a la exacta determinación de los derechos que surgen de este tipo de garantías. En ese orden de ideas, la constitucionalización de la iniciativa para desarrollar cualquier actividad económica, le asegura al individuo un conjunto de derechos deducibles o, al menos, íntimamente relacionados con el libre ejercicio de aquélla, de modo tal que la libertad empresarial o económica debiera entenderse congruente con esa variada gama de derechos. Por cierto, el destinatario central del reconocimiento de estos atributos será la persona física; pero nada impide que estos derechos sean reconocidos también a "aquella unidad de voluntad jurídicamente constituida que conforme al Derecho toma las decisiones determinantes para la empresa, es decir, la persona jurídica o sociedad mercantil en cuyo nombre y por cuya cuenta y riesgo otras personas desempeñan actividades empresariales" 45 . Los derechos que dimanan del contenido esencial de la libertad de empresa se relacionan con variadas disciplinas jurídicas. Los más recurrentes, por cierto, son aquellos que se vinculan directamente con la actividad comercial y económica; pero si su contenido sólo se redujera a ese tipo de derechos, lo cierto es que existiría una serie de facultades y atributos que no podrían ser explicados cabalmente en base a otro tipo de garantías.

Ello ocurre, por ejemplo, con los derechos que asume el empresario en tanto empleador. En efecto, muchas de las facultades que éste adquiere en el ámbito de las relaciones laborales se pueden explicar de manera importante (aunque no exclusiva) desde la óptica de la libertad establecida en el artículo 19 No 21 CPR. La existencia de relaciones en el marco de una empresa predetermina el ingreso del trabajador dentro de una organización específica, donde existe una estruc-

44 Cfr. en el plano doctrinal Martín-Retortillo (1988), p. 171.

45 Vid. Benda et al. (1996), p. 583. Si bien la Constitución chilena carece de un precepto al estilo del artículo 19.3 de la Constitución alemana, el cual extiende los derechos fundamentales "a las personas jurídicas nacionales en la medida en que, según su respectiva naturaleza, les sean aplicables”, de todas formas deberá entenderse que la libertad de empresa se aplica a estas entidades en virtud de la concepción institucional de los derechos fundamentales. Sobre el particular, vid. por todos CRUZ (1992), pp. 67 y siguientes; y Nogueira (1997), pp. 152 y ss. 
tura jerarquizada que da cuenta de las atribuciones de un titular. ${ }^{46}$ Dentro de esa estructura, existe un reparto de competencias e, incluso, una delegación de funciones de acuerdo a la complejidad que tenga la organización, las cuales se manifiestan en potestades generales de ordenación, dirección y disciplina. Parte importante de esas facultades organizativas permiten configurar al empleador no sólo como un acreedor de trabajo sino que, también y ante todo, como un titular que puede dirigir tanto las singulares prestaciones de trabajo como la organización general de la empresa. ${ }^{47}$

De esta forma, el artículo 19 No 21 CPR permite comprender el ejercicio de poderes y facultades íntimamente vinculadas a la condición de empleador y que, probablemente, no podrían entenderse de manera completa con la mera referencia de la libertad de trabajo (art. 19 No 16 CPR). De allí la importancia de reconocer que, dentro del contenido esencial de la libertad de empresa, cohabitan un conjunto de derechos de carácter laboral que explican la idea jurídica de empleador.

\section{La titularidad sobre los bienes destinados a la producción}

El ejercicio de la libertad económica lleva implícito la titularidad sobre un conjunto de derechos o facultades que habilitan al empresario para organizar y sostener una actividad productiva. Sin esa titularidad sería imposible pretender el goce amplio de una serie de atribuciones que trasuntan la condición de acreedor laboral y que se reflejan fundamentalmente en la capacidad del sujeto para dirigir $\mathrm{y}$ ordenar los diversos factores que intervienen en el ámbito empresarial ${ }^{48}$.

La titularidad del empresario deriva esencialmente del ordenamiento jurídico y del contrato que dio origen a su condición de titular, elementos todos que permiten dotarlo de un haz de derechos y obligaciones que conforman el marco general dentro del cual puede actuar el sujeto. La titularidad, por cierto, no supone ostentar necesariamente la condición de propietario sobre los bienes ya que existen numerosas otras figuras suficientemente aptas para fundamentar en un individuo sus derechos en la actividad productiva ${ }^{49}$. Dicha titularidad permite

46 Cfr., Román (1992), pp. 62 y 86. Vid., también, Miñambres (1985), p. 28; y Valdés (1990), pp. 280 y 281.

47 Vid., Montoya (1965), pp. 198, 208 y 209.

48 Cfr. Fernández (2004), p. 25.

49 Cfr., por todos, Álvarez (1992), p. 397; Cidoncha (2006), p. 209; GonZalez (1989), p. 134; Miñambres (1995), pp. 136 y 140; Montoya (1965), p. 198, y Rey (1994), p. 329. 
explicar, independientemente de un eventual vínculo dominical sobre los bienes de producción, la capacidad que ostenta el empresario para ejercer los poderes propios de ordenación ${ }^{50}$. Sólo en esa lógica se pueden explicar las atribuciones de que goza el arrendatario, el usufructuario o el poseedor útil de los bienes, o aquel que simplemente asume la calidad de empresario con capitales ajenos ${ }^{51}$. Lo relevante, en consecuencia, es que el empresario aparece en la actividad productiva como titular de los diversos elementos; pero dicha titularidad podrá ser distinta en relación a cada uno de los factores integrantes de la empresa; y todas estas titularidades, eventualmente heterogéneas, se refieren en uno de sus polos personales a un mismo sujeto ${ }^{52}$.

Con todo, no se puede dejar de soslayar la relevancia que adquiere en el ámbito de la libertad económica la concurrencia de una titularidad dominical. El dominio, históricamente, se ha erigido como el más genuino precedente que habilita la iniciación de una actividad productiva, ocupando un lugar central en la determinación del concepto de constitución económica ${ }^{53}$. Por ello, si bien el ejercicio de la libertad de empresa no presupone la existencia de un propietario en sentido estricto, al menos sí permite complementar ambas figuras en el entendido de que la propiedad logra justificar en la mayor parte de los casos el ejercicio de esta libertad.

Como es sabido, la propiedad se fundamenta en la idea de que toda persona goza de un derecho general para adquirir (“derecho a la propiedad”) y conservar el dominio de bienes ("derecho de propiedad") 54 , ya sea en su fase de producción o de consumo. Ese derecho se trasunta en una titularidad específica que habilita al sujeto para aprovechar o explotar los bienes, ejercer facultades específicas de acuerdo a la ley, así como para desarrollar su actividad bajo las bases materiales de la libertad, ya que sólo de esa manera puede realizar cabalmente su atributo ${ }^{55}$. Si el empresario ostenta la titularidad del dominio, así como cualquier otra que le habilite a desarrollar su actividad, entonces gozará de una efectiva autonomía para explotar y aprovechar los bienes sobre los cuales ejerce sus potestades, cuestión

\footnotetext{
50 Cfr. en este sentido López (1979), p. 19; y RoMÁn (1992), p. 125.

51 Cfr. Álvarez (1992), p. 397; Girón (1985-1986), pp. 25 y 28, y MarTin (1981), p. 15.

52 Vid. Albiol (1984), p. 10.

53 Cfr. Rey (1984), pp. 196 y 318. Vid. también Irarrázaval (1987), p. 100.

54 Cfr. artículo 19 No 23 y 19 No 24 de la Constitución.

55 Cfr. Barnes (1988), pp. 49, 51, 80 y 89. Vid. también, Rey MarTínez (1984), p. 146.
} 
imprescindible al momento de explicar la noción constitucional de la libertad de empresa ${ }^{56}$. Esa autonomía, removidos sus obstáculos por la acción de los poderes públicos, permite a los individuos participar en la vida económica del país.

Y en esta línea-aunque sin especificar las formas concretas de dicha propiedad, ni menos definirla-57 se expresa el artículo 19 No 24 de la Constitución, cuando reconoce a todos los individuos el derecho a la propiedad con la correspondiente delimitación de la función social ${ }^{5}$. De ese modo, se hace accesible a todas las personas "el disfrute de los bienes económicos en general y la propiedad de los bienes de producción en particular" 59 . El empresario podrá decidir el destino de aquellos bienes sobre los cuales ostenta la condición de dominus, ordenándolos para un fin productivo determinado. Él goza, producto de este derecho, de una amplia libertad para determinar el destino final de los bienes, pudiendo conducirlos según la mejor conveniencia económica de los mismos. Tan relevante es esta garantía que, en el ordenamiento jurídico clásico, importó el fundamento de la libertad económica y política. Un claro ejemplo de ello se encuentra en el artículo 544 del Código de Napoleón, del año 1804, que definió a la propiedad como "el derecho de gozar y de disponer de las cosas de la forma más absoluta, siempre que no se haga de ellas un uso prohibido por las leyes o por los Reglamentos"60. Es decir, se reconocía de manera amplia la titularidad dominical, con afirmación erga omnes, y teniendo presente que las limitaciones sólo podían interpretarse de manera restrictiva.

Sin embargo, los derechos económico-sociales le imprimieron a la propiedad una finalidad eminentemente social que rompe el esquema del individualismo jurídico, a objeto de compatibilizar el derecho propio de toda persona con el de-

\footnotetext{
56 Cfr., Ribera (2007), pp. 286 y 287.

57 Cfr. Cea (2004), p. 523. Aunque referido a textos comparados, vid. también Pérez (1983), p. 383.

58 En sus incisos pertinentes, el citado artículo 19 No 24 CPR señala expresamente: "La Constitución le asegura a todas las personas: $24^{\circ} \mathrm{El}$ derecho de propiedad en sus diversas especies sobre toda clase de bienes corporales o incorporales (inc. $1^{\circ}$ ). Sólo la ley puede establecer el modo de adquirir la propiedad, de usar, gozar y disponer de ella y las limitaciones y obligaciones que deriven de su función social. Ésta comprende cuanto exijan los intereses generales de la Nación, la seguridad nacional, la utilidad y la salubridad públicas y la conservación del patrimonio ambiental (inc. $2^{\circ}$ ). Nadie puede, en caso alguno, ser privado de su propiedad, del bien sobre que recae o de alguno de los atributos o facultades esenciales del dominio, sino en virtud de ley general o especial que autorice la expropiación por causa de utilidad pública o de interés nacional, calificada por el legislador (...)".
}

59 Cfr. Barnes (1983), p. 69.

60 Vid. Bassols (1988), p. 113. 
recho de terceros y de la sociedad en general. Si la propiedad se justificaba como el medio más idóneo y eficiente en la gestión de los bienes económicos, ésta no podía abandonarse al puro arbitrio del propietario debiendo alzarse con un marcado fin social que pondere y califique proporcionalmente el interés individual y el de la comunidad organizada ${ }^{61}$. De este modo, la propiedad ya no podía concebirse como un omnímodo derecho de libertad, autónomo y absoluto; sino que como una expresión de la finalidad social que le ha otorgado el constituyente. ${ }^{62}$ Este carácter social no sólo se encuentra reconocido en el artículo 19 No 24 CPR, sino que además en la propia definición del Estado que efectúa el artículo $1^{\circ}$ de la Constitución.

Esto viene a dejar en evidencia que la configuración actual de la propiedad ya no puede ser estructurada como un derecho absoluto. El conjunto de prerrogativas y facultades que supone el dominio debe ser compatibilizado con los deberes y las obligaciones que se derivan de su función social63. Y es esa característica la que delimita el contenido propio del derecho de propiedad, definiendo su sustancia y configuración constitucional ${ }^{64}$. Lo anterior obliga a circunscribir el reconocimiento jurídico del dominio a dos dimensiones distintas de una misma realidad: como un derecho subjetivo y, a la vez, como un instituto jurídico privado, siendo esto último una consecuencia de la función social de los bienes.

Con todo, hay que recalcar que la existencia de limitaciones no puede llevar a suponer que la propiedad no constituye un derecho subjetivo ${ }^{65}$; por el contrario, la regulación actual de la propiedad obliga a ver en ella un haz de atribuciones que deben complementarse con el presupuesto de un verdadero Estado social de Derecho. Dicho de otra manera, en la función social se produce la adecuada complementariedad entre el interés del titular propietario y el de la entera colectividad ${ }^{66}$.

Lo que ocurre es que el goce individual del dominio debe ser compatibilizado con la legítima aspiración de todos los integrantes de la sociedad de servirse de los bienes materiales y a participar en la vida económica. Y esto se consigue

61 Cfr. entre otros Bassols (1988), pp. 114 y 125; Rey (1994), p. 294, y Rivero (1986), p. 50.

62 Cfr. Rey (1994), p. 191. Vid. también Golg (1996), p. 738.

63 Cfr. SÁnchez (1992), p. 129.

64 Cfr. Barnes (1988), pp. 47 y 87. Vid. también, Rey (1994), p. 295.

65 Cfr. De los Mozos (1993), p. 229.

66 Cfr. Barnes (1988), pp. 66, 107 y 108. Vid. también Golg (1996), p. 734. 
precisamente con la regulación constitucional de la función social. Ello permite delimitar el derecho, así como conciliar el ejercicio de la titularidad con la existencia de otras facultades, cuestión que adquiere mayor sentido en una comprensión social de la propiedad ${ }^{67}$.

En esta perspectiva, la libertad de adquisición y producción de los bienes puede ser limitada, siendo perfectamente compatibles con el uso de la propiedad, la exigencia de autorizaciones, deberes legales, así como la mantención de determinadas condiciones generales de funcionamiento por parte de la autoridad pública. Lo importante es que en el ejercicio de esas atribuciones, la Administración actúe de acuerdo al principio de legalidad que la propia Constitución establece ${ }^{68}$.

La consagración constitucional de la propiedad supone, también, un reconocimiento a todos los individuos para adquirir libremente las materias primas, semielaboradas, patentes y energías que sean necesarias para el proceso económico $^{69}$. De igual modo, el propietario de bienes productivos goza de un derecho para acometer la creación de empresas determinadas, asumir la titularidad de la organización y de los bienes que le pertenecen, así como ejercer un derecho al beneficio que se origine del desempeño lícito de su actividad ${ }^{70}$.

Si se tiene libertad para emprender actividades económicas, también se tiene facultad para la libre fundación de empresas lícitas y para acceder en igualdad de condiciones al mercado de bienes y servicios. La libertad de empresa, en síntesis, supone una libertad para crear o extinguir organizaciones productivas, sin perjuicio de las limitaciones derivadas de la función social las que deben ser consideradas como parte integrante de su configuración.

Todo esto trae como consecuencia obligada el hecho de que exista una evidente relación entre libertad de empresa y derecho de propiedad, toda vez que el reconocimiento de este último derecho constituye un requisito relevante, aunque no exclusivo, para el adecuado disfrute de la libertad económica ${ }^{71}$.

\section{Derecho a la libre competencia en el mercado}

Una de las notas características de cualquier empresa es que los bienes y servicios que ella elabora se producen para el mercado, concurriendo en forma libre

67 Cfr. De los mozos (1993), p. 244.

68 Cfr. Montoya (1995), p. 61.

69 Cfr. Martínez (1983), p. 3189; y Martínez (1983), p. 667.

70 Cfr. Rey (1994), pp. 275 y 329.

71 Cfr., por todos, García-Pelayo (1979), p. 33. 
al encuentro de la demanda ${ }^{72}$. Ello da como resultado la existencia de una instancia económica con libertad de competencia, a objeto de que todos los agentes accedan en igualdad de condiciones a los bienes y servicios que se producen ${ }^{73}$. El presupuesto jurídico de esa competencia es la propia libertad económica, en cuya virtud se crean las condiciones externas necesarias para el libre establecimiento de relaciones económicas y jurídicas en el tráfico mercantil ${ }^{74}$. Por ello quedan fuera del ámbito de protección de la libertad de empresa los intercambios productivos que se realizan fuera del mercado (v. gr., los trabajos altruistas o de mera vecindad $)^{75}$.

Una economía abierta implica la acción efectiva de los poderes públicos, a fin de evitar aquellas prácticas que puedan afectar o dañar seriamente el principio de igualdad jurídica que se aplica a todos los agentes económicos que participan dentro del sistema constitucionalmente diseñado. La verdad es que en la actualidad los mercados se manifiestan en diversas ocasiones de modo imperfecto, permitiendo los acuerdos entre empresas independientes, o asociaciones de empresas, concluidos para alcanzar un objetivo común que restrinja o elimine la competencia de ciertos bienes o servicios en el mercado ${ }^{76}$. Con este fin, se pretende la regulación de los precios y las condiciones de venta, limitando o reduciendo la capacidad de producción y reparto de los mercados y esferas de influencia.

Los efectos dañinos que este tipo de prácticas producen en los sistemas económicos ha traído como consecuencia la intervención de la autoridad o del ordenamiento jurídico, a fin de asegurar el buen funcionamiento de esos mercados ${ }^{77}$. Dicha intervención no busca imponer al mercado una determinada finalidad o beneficiar irracionalmente a ciertos sectores en menoscabo de otros; sino que, lisa y llanamente, lo que se pretende es defender el libre juego de la oferta y la demanda como un instrumento de interés general, eficaz y adecuado, en la libre participación de los agentes económicos. Cuando la participación así planteada fracasa, entonces el Estado interviene a objeto de que los principios que subyacen

\footnotetext{
72 Vid. Cidoncha (2006), p. 148: "Lo que no puede existir nunca es competencia económica sin mercado".

73 Cfr. Cea (1991), p. 25.

74 Cfr. Font (1987), p. 61.

75 Cfr. García (2008), p. 146.

76 Vid. Guerrin; Kyriazis (1994), p. 272.

77 Cfr. torres del moral (1998), p. 565.
} 
en el Estado democrático de Derecho prevalezcan. Y es precisamente la defensa de la libre competencia económica -manifestada en una legislación tendente a prevenir o castigar jurídicamente aquellas situaciones que constituyan obstáculos para el normal desarrollo de la competencia dentro del mercado-, una necesaria herramienta de protección, y no de restricción, frente a los desajustes económicos y la concurrencia entre empresas ${ }^{78}$.

En nuestro país, estas consideraciones se han visto reflejadas, en el plano legal, en la Ley No 20.169, de 16 de febrero de 2007. Dicho cuerpo legal vino a establecer una normativa amplia y sistematizada, definiendo además los actos de competencia desleal. En esta perspectiva, la Ley No 20.169 indicó que, en general, constituía acto de competencia desleal toda conducta contraria a la buena fe o a las buenas costumbres que, por medios ilegítimos, persiga desviar clientela de un agente del mercado. En particular, se consideraron como actos de competencia desleal, entre otros (i) Toda conducta que aproveche indebidamente la reputación ajena, induciendo a confundir los propios bienes, servicios, actividades, signos distintivos o establecimientos con los de un tercero; (ii) El uso de signos o la difusión de hechos o aseveraciones, incorrectos o falsos, que induzcan a error sobre la naturaleza, proveniencia, componentes, características, precio, modo de producción, marca, idoneidad para los fines que pretende satisfacer, calidad o cantidad y, en general, sobre las ventajas realmente proporcionadas por los bienes o servicios ofrecidos, propios o ajenos; (iii) Todas las informaciones o aseveraciones incorrectas o falsas sobre los bienes, servicios, actividades, signos distintivos, establecimientos o relaciones comerciales de un tercero, que sean susceptibles de menoscabar su reputación en el mercado. Son también ilícitas las expresiones dirigidas a desacreditarlos o ridiculizarlos sin referencia objetiva; (iv) Las manifestaciones agraviantes que versen sobre la nacionalidad, las creencias, ideologías, vida privada o cualquier otra circunstancia personal del tercero afectado y que no tenga relación directa con la calidad del bien o servicio prestado; (v) Toda comparación de los bienes, servicios, actividades o establecimientos propios o ajenos con los de un tercero, cuando se funde en algún antecedente que no sea veraz y demostrable, o cuando de cualquiera otra forma infrinja las normas de esta ley; (vi) Toda conducta que persiga inducir a proveedores, clientes u otros contratantes a infringir los deberes contractuales contraídos con un competidor;

\footnotetext{
78 Vid. por todos De Gispert (1989), pp. 48 y ss.; GIRÓN (1985-1986), pp. 102 y 103, y ZAMORA (1986), p. 367.
} 
y (vii) El ejercicio manifiestamente abusivo de acciones judiciales con la finalidad de entorpecer la operación de un agente del mercado ${ }^{79}$.

Lo anterior es congruente con lo preceptuado en el DFL No 1, de 2005, del Ministerio de Economía, Fomento y Reconstrucción, el cual fijó el texto refundido, coordinado y sistematizado del Decreto Ley No 211, de 1973. El artículo $3^{\circ}$ de dicho cuerpo legal sanciona al que ejecute o celebre, individual o colectivamente, cualquier hecho, acto o convención que impida, restrinja o entorpezca la libre competencia, considerando como tales los acuerdos expresos o tácitos entre competidores, o las prácticas concertadas entre ellos, que les confiera poder de mercado y que consistan en fijar precios de venta, de compra u otras condiciones de comercialización, limitar la producción, asignarse zonas o cuotas de mercado, excluir competidores o afectar el resultado de procesos de licitación. También se consideran atentatorios de la libre competencia la explotación abusiva de una posición dominante en el mercado, fijando precios de compra o de venta, imponiendo a una venta la de otro producto, o la realización de prácticas predatorias, o de competencia desleal, "realizadas con el objeto de alcanzar, mantener o incrementar una posición dominante".

De este modo, la defensa de la libre participación de los agentes económicos comprende toda la normativa destinada a la protección de la libertad de competencia, mediante la prevención y, en su caso, la represión, de las situaciones que constituyan obstáculos creados por decisiones empresariales para el desarrollo de la misma en el mercado. El objetivo de esta legislación apunta, por tanto, a la defensa de la libertad de empresa contra aquellas prácticas, acuerdos, conductas o actuaciones que pudiesen atentar al libre funcionamiento de los agentes económicos dentro del mercado 80 .

En doctrina, y analizada teóricamente, la competencia económica implica las siguientes alternativas ${ }^{81}$ : (i) El derecho a ingresar a un determinado mercado de productos y comerciarlos con otros individuos, de manera que a ellos pueda acceder cualquier sujeto; (ii) La existencia de un considerable número de unidades económicas, tanto en la oferta como en la demanda; (iii) Homogeneidad de los productos o servicios que se ofrecen al mercado; (iv) Ausencia de un poder de control sobre los precios, el cual se forma según el libre juego de la oferta y la demanda; (v) Transparencia del mercado, a objeto de que los actuales o futuros

79 Con respecto a los alcances de la Ley No 20.169, vid. GonZÁLEZ (2007), pp. 15 y ss.

80 Cfr. Paz-Ares; Alfaro (2008), p. 983.

81 Vid. Font (1987), p. 34. Cfr., además, Martínez (1983), pp. 667 y 668. 
compradores y vendedores estén informados de las características generales de los productos y las condiciones para acceder a ellos; (vi) La libre movilidad de los factores de producción; (vii) La obtención de un máximo beneficio y utilidad, tanto de los consumidores como de los empresarios, y (viii) La posibilidad de acceder al crédito y a vías de financiamiento en un mercado libre de capitales, en condiciones de igualdad con los demás agentes económicos del sector privado y de las empresas públicas.

No obstante, esta visión "pura" de la competencia no se ha dado nunca en los mercados económicos, reconociéndose la permanencia de ciertos grados de competencia imperfecta o monopolística, que provoca distorsiones evidentes en el juego de la oferta y la demanda. Por ello, en nuestros días, lo que verdaderamente distingue a las economías abiertas es un libre acceso al mercado, la libre circulación de mercancías, personas, servicios y capitales, así como la multiplicidad de empresarios; la existencia de un cierto grado de competitividad entre las empresas, y una significativa intervención estatal, tanto como órgano regulador de la vida económica de los diversos sectores industriales, así como empresario activo en determinados casos.

Entre los elementos negativos de la competencia imperfecta actual, es preciso destacar la falta de homogeneidad de los productos o servicios, encontrándonos con bienes eminentemente sustituibles; la presencia en cada mercado de los denominados poderes económicos que controlan o manipulan las condiciones generales de cambio y contratación de bienes y servicios, y la tendencia a la concentración de grandes empresas, cuestión que provoca situaciones monopolísticas configuradoras de la estructura y funcionamiento del mercado económico ${ }^{82}$.

En definitiva, la libre competencia dentro de un contexto de libertad económica debe contener principios tales como la prohibición de carteles y prácticas restrictivas de la misma; el establecimiento de un límite a la concentración empresarial, tanto horizontal como vertical, y el establecimiento de responsabilidades y sanciones para el caso de atentados en contra de ella ${ }^{83}$. Todos estos principios de ordenación económica deben tender a que el empresario mejore indefinidamente su oferta, concluyendo los contratos, los actos preparatorios de éstos, determinando las prestaciones objeto de los actos jurídicos que celebre, entre otros varios aspectos ${ }^{84}$, ya que la libertad económica no puede ser entendida como un derecho que faculte para

82 Cfr. Font (1987), pp. 37 y ss.

83 Cfr. ARIÑo (1995), pp. 118 y 119.

84 Cfr. Fernández-Novoa (1965), p. 27. 
restringir la competencia en el mercado. De esta forma, la Constitución plantea como objetivo la eliminación de aquellas prácticas y maquinaciones que tienden a falsear los productos ofrecidos al consumidor o a desequilibrar fraudulentamente los precios ${ }^{85}$. Esa eliminación redunda en una mayor libertad del tráfico negocial, en una coordinación de los planes económicos, así como en la verificación de un proceso global que se opera a través de los precios del mercado ${ }^{86}$.

Las consideraciones anteriores tienen correspondencia directa con las restricciones impuestas por la normativa laboral a las actuaciones del empresario, toda vez que esta última legislación también ordena el funcionamiento del mercado de trabajo dejando en evidencia una intervención del Estado en dicho funcionamiento. A mayor abundamiento, el ordenamiento laboral también es un mecanismo de regulación de competencia en el mercado, asegurando -en este ámbito- la igualdad de condiciones entre todas las empresas que participan en el mismo ${ }^{87}$.

\section{La libertad de contratación}

Desde una perspectiva amplia, la facultad de contratación se traduce en una posibilidad cierta de pactar, convenir o comerciar bienes y servicios, con plena sujeción a los principios de libre competencia y no discriminación que establecen la Constitución y las leyes. Esta libertad contractual le permite a toda persona vincularse jurídicamente con otros, respetando por cierto las prerrogativas de terceros en el ejercicio de sus derechos fundamentales. De este modo, la libertad contractual se refleja como la más genuina expresión de la autonomía privada que impregna la totalidad del Derecho común, y que le reconoce al individuo una efectiva independencia en la configuración de las relaciones económicas ${ }^{88}$.

La libertad de contratación presupone, asimismo, una amplia facultad de inversión por parte del empresario, a fin de colocar el capital o los bienes en el sector e industria que a su juicio sea más adecuado ${ }^{89}$. Esta libertad se expresará, por tanto, en la creación de una nueva empresa, en la ampliación del capital existente, en la aplicación de diversas medidas de contratación, en la elección de proveedores y

\footnotetext{
85 Cfr. Balado (1994), p. 54.

86 Cfr. BENDA et al. (1996), p. 564.

87 Vid. Rivas; Rodríguez-Piñero Royo (2006), pp. 764 y 767.

88 Cfr. por todos Irureta (2006), pp. 61 y ss.

89 Cfr. Ribera (2007), p. 282.
} 
clientes de sus mercancías, así como en la fijación de los precios de acuerdo a las necesidades del mercado económico, entre otras varias manifestaciones ${ }^{90}$.

Dentro de un contexto estrictamente laboral, la libertad de contratación importa para el empresario el reconocimiento de una facultad amplia para celebrar relaciones jurídicas de trabajo, de acuerdo a criterios objetivos de idoneidad y capacidad, pudiendo a tal efecto seleccionar personal, fijar los sistemas de rendimiento, promoción y ascenso, así como dictar las normas de dirección y disciplina que la empresa o la actividad tengan ${ }^{91}$. Para el trabajador, en tanto, la libertad de contratación supone la prohibición del denominado trabajo forzoso ${ }^{92}$. Esto viene a dejar en evidencia como es lógico que la libertad de contratación no se refiere solamente a los empresarios, sino que también, y sobre todo, a los trabajadores, ya que la imposición del deber de contratar sería evidentemente contraria a la Constitución, de conformidad con lo establecido en el artículo 19 No 16 CPR, sobre libertad de trabajo. ${ }^{93}$ Asimismo, la obligatoriedad de la contratación por parte del trabajador se opondría a lo dispuesto en el artículo $4^{\circ}$ de la Declaración Universal de Derechos Humanos (en relación con la prohibición de trabajos forzados).

A pesar del alcance amplio de esta facultad, las relaciones laborales que se pacten en virtud de ella exigen que los sujetos del contrato de trabajo actúen bajo esquemas de respeto a las normas legales de carácter general emanadas del poder público, en especial las relativas a la irrenunciabilidad de derechos laborales y a la no discriminación ${ }^{94}$. De esta forma, el empresario se encuentra obligado a actuar conforme a una noción jurídica de equidad y justicia, tanto en la concreción de un contrato de trabajo determinado como en las exigencias generales que emanan del vínculo contractual que mantenga con los trabajadores. A fin de cuentas, el margen de autonomía de un contratante varía en razón del tipo de contrato y de la regulación que le es aplicable; y desde esa perspectiva, hasta el propio ordenamiento civil ha evolucionado en su concepto de libertad contractual ${ }^{95}$.

90 Cfr. De Juan (1984), pp. 154 y 155.

91 Cfr. Del Valle (1993), p. 185; Martínez (1983), p. 668, y Martínez (1985), p. 3191.

92 Cfr. Manrique (1994), p. 37. Vid., también, Menezes (1994), p. 570.

93 Cfr. Ribera (2007), p. 285.

94 Como ha señalado la jurisprudencia, la libertad de contratación no reconoce a las partes una libertad absoluta para fijar las condiciones en que están llamadas a realizar una operación, acto o negocio (cfr. sentencia de la Corte Suprema, Rol No 20.257, de 13 de mayo de 1986.

95 Cfr. Rodríguez-Piñero; Bravo-Ferrer (2003), p. 6061. 
En el ejercicio de esta libertad de contratación -y en lo que respecta al manejo de la actividad productiva- el empresario goza de un doble derecho. Por una parte, tiene atribuciones para decidir si contrata o no a un trabajador determinado, así como para prorrogar la vigencia de contratos temporales o transformar a éstos en relaciones jurídicas de tiempo indefinido ${ }^{96}$. Y por otra, el empresario se encuentra facultado para elegir libremente a un trabajador concreto, que él considere más idóneo para los servicios que requiere la empresa, respetando por cierto los criterios de no discriminación y racionalidad que exigen la norma constitucional y el Código del Trabajo ${ }^{97}$. Por cierto, aquí no se trata de establecer una exigencia absoluta de igualdad, en el entendido de que todas las decisiones empresariales se sometan a una revisión específica. Más bien, lo que se busca es privilegiar un sistema de relaciones laborales en que el empresario utilice su libertad contractual de forma equilibrada y no discriminatoria.

\subsection{La fijación de dotaciones como presupuesto de la libertad contractual}

El primer aspecto de este derecho empresarial se manifiesta fundamentalmente en la fijación de dotaciones de personal y en la amortización de vacantes. Si en virtud de la titularidad de que goza el empresario en la actividad productiva, éste puede establecer los niveles de puestos de trabajo y las reales necesidades de nuevas contrataciones, entonces también le corresponderá fijar inicialmente $-\mathrm{y}$ revisar con posterioridad, ya sea ampliándolas o reduciéndolas- las plantillas o dotaciones de la empresa ${ }^{98}$.

Con todo, esta facultad no puede ser entendida de forma ilimitada. Si bien el empresario, en razón de la libertad de empresa, tiene atribuciones para fijar las dotaciones y tomar decisiones en cuanto al tipo de contratación, existen una serie de limitaciones, tanto de carácter heterónomo como autónomo, en el ejercicio de esta facultad. Estas restricciones, de evidente connotación imperativa,

\footnotetext{
96 Salvo, por cierto, los casos en que la ley presume la existencia de una relación laboral indefinida. Cfr. en este sentido GarCía (1993), p. 1013.

97 En palabras de la jurisprudencia, el empresario posee un derecho a la libre contratación de su personal, a determinar las modalidades de su trabajo y su forma de planificarlo, y a fijar los términos de los contratos cuidando que se respeten las normas legales vigentes (vid. sentencia de la CorTe Suprema, Rol No 17.804, de 5 de diciembre de 1991. La misma doctrina puede consultarse en la sentencia de la CORTE Suprema, Rol No 17.660, de 23 de octubre de 1991. Cfr., también, en el plano doctrinal Alemany (1988), pp. 2108 y 2110.
}

98 Vid. SALA (1995), p. 311. 
se traducen en una mayor rigidez en relación con la flexibilidad que supone la libertad de empresa.

Entre las limitaciones a la libertad de contratación empresarial se encuentra, por ejemplo, el artículo 18 de la Ley No 19.262, sobre plena integración social de personas con discapacidad, de 14 de enero de 1994, según el cual los "establecimientos educacionales, organismos públicos y privados de capacitación, empleadores y en general toda persona o institución, cualquiera que fuere su naturaleza, que ofrezca cursos, empleos, servicios, llamados a concurso y otros similares, exigiendo la rendición de exámenes u otros requisitos análogos, deberán adecuar los mecanismos de selección en todo cuanto sea necesario para permitir la participación de las personas con discapacidad en igualdad de oportunidades". Asimismo, el artículo 34 del referido cuerpo legal indica que las personas con discapacidad inscritas en el Registro Nacional de la Discapacidad, podrán celebrar el contrato de aprendizaje contemplado en el artículo 77 del Código del Trabajo, hasta la edad de 24 años. Y agrega: "Cuando el Estado, en conformidad con lo dispuesto en el Párrafo 3 del Título 1 del Decreto Ley No 1446, de 1976, cuyo texto refundido, coordinado y sistematizado fue fijado por el Decreto con Fuerza de Ley No 1, de 1989, del Ministerio del Trabajo y Previsión Social, financie total o parcialmente programas de capacitación, se contemplarán las medidas necesarias para permitir la participación de personas con discapacidad, sin limitación de edad". En igual sentido, el artículo 59 del Código Aeronáutico faculta a la autoridad administrativa para determinar, por razones de seguridad de vuelo, el número del personal aeronáutico que debe operar cualquier aeronave, previo examen de las características de ésta y estudio de la operación de vuelo.

Dentro de estos límites, también destacan las normas sobre empresas de servicios transitorios contenidas en la Ley No 20.123, de 16 de octubre de 2006; el artículo 62 de la Ley General de Cooperativas, de 17 de noviembre de 2004, y las políticas de fomento del empleo de determinados trabajadores ${ }^{99}$. A ello se podrían agregar las limitaciones que establece el Código del Trabajo en materia de contratación de trabajadores extranjeros ${ }^{100}$. De igual forma, la libertad para modificar las dotaciones o reducir personal - con posterioridad a la contrata-

99 En lo que respecta a las medidas de fomento del empleo, éstas pueden ser de dos clases: (i) Mediante concesión de subvenciones a las empresas contratantes de trabajadores según determinados requisitos de fondo y forma, y (ii) Mediante concesión de bonificaciones en las cuotas a pagar a la seguridad social por los empresarios de aquellos trabajadores contratados bajo ciertas circunstancias.

100 Artículos 19 y 20 CT. 
ción- se ve fuertemente condicionada en materia de despidos, ya que el sistema chileno establece un marco regulatorio fundado inicialmente en la estabilidad en el empleo.

\subsection{La libre elección de los trabajadores}

Un segundo aspecto de la libertad de contratación es el concerniente a la libre elección de trabajadores. Ella se traduce en una posibilidad cierta del empresario para efectuar la contratación de aquel trabajador que estime más adecuado a las necesidades que tiene la empresa ${ }^{101}$. Sin embargo, esta libertad, al igual que en el caso anterior, tampoco puede ser entendida de manera absoluta, ya que encuentra importantes limitaciones en materia de colocación ${ }^{102}$, superación de pruebas de selección ${ }^{103}$, ofertas públicas de empleo ${ }^{104}$, o la realización de determinados cursos de capacitación.

Las normas sobre no discriminación constituyen, también, una importante limitación en el ejercicio de esta facultad empresarial. Tanto el artículo 19 No 16 de la Carta de 1980 -en su perspectiva de regla general de igualdad y prohibición de discriminación-, como el artículo $2^{\circ}$ del Código del Trabajo, consagran expresamente este principio, y establecen -en el caso de este último- un claro enunciado de cuáles son las prácticas sancionadas por el legislador ${ }^{105}$. A lo anterior se une el hecho que Chile se encuentra entre aquellos países que han ratificado los Convenios $\mathrm{No}_{\text {s. }}$ 111, de 1958, y 122, de 1964, ambos de la OIT, la Declaración Universal de los Derechos Humanos, de 1948, y el Pacto Internacional de Derechos Civiles y Políticos, de 1966. Todos estos instrumentos establecen normas antidiscriminatorias a las cuales se encuentra obligado el ordenamiento jurídico chileno ${ }^{106}$. De esta forma, la prohibición de discriminación no sólo alcanza a la

101 Cfr. sentencia de la Corte Suprema, Rol No 17.804, de 5 de diciembre de 1991.

102 Cfr. Ley No 20.123, de 16 de octubre de 2007.

103 Vid. por todos Fernández (1994), pp. 510 y ss.

104 Vid. por todos IrURETA (2008), pp. 47 y ss.

105 La norma del artículo $2^{\circ}$ del Código del Trabajo debe ser complementada con la disposición establecida en el artículo $1^{\circ}$ de la Ley No 20.575, que Establece el principio de finalidad en el tratamiento de datos personales (DO de 17 de febrero de 2012), según el cual no podrá requerirse, en los procesos de selección de personal, información comercial del postulante a un cargo o empleo. De igual forma, cfr. artículo $2^{\circ}$ de la Ley No 20.609, que establece medidas contra la discriminación (DO de 24 de julio de 2012).

106 Cfr. SAla Franco (1995), pp. 323 y 324. Los límites a la libertad de contratación en razón de la no discriminación encuentran respaldo explícito o tácito, también, en las Constituciones de Portugal, España, Grecia, 
actividad legislativa o a la acción de los poderes públicos, sino que también ella resulta aplicable a las decisiones que toma el empresario ${ }^{107}$.

La no discriminación, aun cuando constituye un principio de carácter general que informa todo el ordenamiento jurídico, adquiere en el ámbito de las relaciones laborales un destacado papel ${ }^{108}$, en cuya virtud los actos empresariales que impliquen una infracción del principio deberán ser considerados actos radicalmente nulos. Lo que se busca, en definitiva, es una condena tajante de la arbitrariedad en el tratamiento desigual. No es que se pretenda excluir una diferenciación razonable, sino la arbitrariedad; y el tratamiento desigual de iguales, en idénticas circunstancias, perjudiciales y sin razón, resulta totalmente arbitrario ${ }^{109}$. De esta forma, en la elección de trabajadores al empresario le estará prohibido diferenciar injustificadamente entre dos o más sujetos, violando o desconociendo los derechos de la persona que se encuentran reconocidos en el ordenamiento constitucional y legal ${ }^{110}$.

En la práctica, por cierto que no será fácil determinar cuándo se está en presencia de un acto de discriminación arbitraria en la contratación de trabajadores, más aún si el contenido valorativo de la igualdad no debiera llevar a suponer una parificación de trato. ${ }^{111} \mathrm{El}$ análisis de la cuestión específica que se objeta deberá enfocarse, por tanto, en función de las particularidades que se manifiestan para cada supuesto concreto. Como señala Palomeque López, para determinar si en un caso específico la diferenciación fue discriminatoria o no, el "sujeto deberá atender, a tal fin, a las circunstancias que concurren en cada supuesto. Para cuya operación dispone de límites señalados (...): 1) el trato diferenciado no puede dar lugar a un resultado que vaya contra derechos y libertades reconocidos en la Constitución; 2) ni, en general, contra cualquier precepto o principio de la mis-

Francia, Alemania, Italia, Luxemburgo, Bélgica, Irlanda y los Países Bajos. En el caso del Reino Unido, si bien no existen derechos generales de igualdad de trato, sí se han consagrado estatutos específicos que prohíben la discriminación por razones de sexo, estado civil y raza. Sobre el particular, vid. ManRIQUe (1994), pp. 37 y 38.

107 Cfr. Rodríguez-Piñero; Bravo-Ferrer (1995), p. 1092; y Rodríguez-Piñero; Bravo-Ferrer (1983), pp. 334 y ss.

108 Cfr. por todos, Conde (1996), pp. 97, 99 y 100; y Rodríguez-Piñero; Bravo-Ferrer (1991), p. 1072.

109 Vid. MarTínez (1998), pp. 97 y ss.

110 Vid. Palomeque (1989), pp. 52 y 53. En el ámbito nacional, cabe tener presente que el Código del Trabajo estableció un procedimiento especial de tutela para los casos en que el empleador ejecute actos discriminatorios (arts. 485 y ss). No obstante, dicho procedimiento quedó circunscrito a las "cuestiones suscitadas en la relación laboral'. De esta forma, se excluyeron del procedimiento de tutela los estadios previos a la contratación.

111 Cfr. Rodríguez-Piñero; Bravo-Ferrer (1991), pp. 1075 y 1089. 
ma; 3) ni, como resulta obvio, contra la esencia del propio principio de igualdad que rechaza toda desigualdad que por su alcance sea irrazonable y por ello haya de calificarse discriminatoria" 112 .

\section{LA LIBERTAD DE ORGANIZACIÓN DE LA EMPRESA}

El ejercicio de la libertad económica supone para el empresario una libre iniciativa en la organización de los elementos productivos. Ese es el aspecto funcional de la constitución de empresas. Si un sujeto tiene atribuciones de establecimiento y creación de unidades económicas, de allí se deriva, también, su facultad de organizarlas y dirigirlas, al objeto de conseguir una estructura básica de la empresa ${ }^{113}$. La titularidad, por tanto, termina manifestándose, entre otros aspectos, en una facultad de organización general que le permite al empresario estructurar ordenadamente la empresa.

La labor de organización da origen a un conjunto de relaciones jurídicas de diversa índole. No sólo están las relativas al ámbito laboral; también existe una organización de los elementos materiales, o de los bienes que utiliza el personal114. Como es sabido, en la mayor parte de las legislaciones se le reconoce a la persona aportante del capital una amplia facultad para organizar y dirigir los factores que intervienen en la empresa, sujetándose a parámetros generales impuestos por la normativa legal, la autonomía colectiva o el contrato de trabajo, en su caso. Y dicha facultad ni siquiera se ve afectada cuando los trabajadores se incorporan en la participación de la empresa ${ }^{115}$. Lo que ocurre es que si la entidad empresarial constituye, de por sí, una organización, el empresario entonces goza de la facultad de ordenar los elementos que en ella intervienen, enlazándolos racionalmente ${ }^{116}$. Por ello, conjuntamente con la posibilidad de crear una entidad para el desarrollo de la actividad económica, existe una atribución para coordinar los diversos factores que participan en una empresa.

De este modo, es el empresario el que determina la forma jurídica que asume la actividad económica, el nombre o la identidad de la empresa, así como la

\footnotetext{
112 Vid. Palomeque (1989), pp. 26 y 27.

113 Cfr. LÓPEZ (1979), p. 23.

114 Cfr. Martínez (1983), p. 668.

115 Cfr. Montoya (1983), p. 129. Vid., también, Román (1992), p. 122.

116 Cfr. FernándeZ-Novoa (1965), p. 8.
} 
constitución interna de la misma ${ }^{117}$. Del catálogo de posibilidades societarias que establece el ordenamiento jurídico, el empresario goza de libertad para optar por aquella que considere más adecuada a sus expectativas, o para crear las filiales y entidades que estime necesarias. Incluso, el reconocimiento se hace extensivo a otras organizaciones atípicas como podría ser el caso de los grupos empresariales.

Con todo, la libertad de organización no puede considerarse de manera aislada. No sólo existe libertad de fundación o establecimiento de actividades económicas, sino también existe libertad para desarrollarlas más allá del mero acto de constitución, asumiendo el sujeto la titularidad de autoorganización y decisión. Si un individuo goza de una protección constitucional con respecto a la titularidad de los bienes de producción y consumo que él ha puesto en movimiento, lógico es suponer que el propio ordenamiento jurídico le reconozca, además, la correspondiente facultad de decisión dentro de los límites que la Constitución y la ley señalan, y que en el caso del artículo 19 No 21 CPR se encuentran claramente especificados: la moral, el orden público, la seguridad nacional y las normas legales que regulan la actividad.

La libertad para desarrollar cualquier actividad económica se traduce, por tanto, en una libertad para iniciar, desenvolver -mediante la forma jurídica que se estime más adecuada-y terminar una actividad empresarial organizada, si tal es la voluntad del agente ${ }^{118}$. En razón de ello, en el acto de libre acceso al mercado, el empresario puede ampliar o reducir su actividad, introduciendo las modificaciones que estime necesarias de acuerdo al funcionamiento de la empresa ${ }^{119}$.

\footnotetext{
117 Cfr. ArIÑo (1995), p. 88. Habrá supuestos, en todo caso, que el ordenamiento podrá exigir que el nombre vaya precedido de la indicación de la actividad. Por ejemplo, el artículo 25 del Decreto Ley No 3.500, que Establece Nuevo Sistema de Pensiones (DO de 13 de noviembre de 1980), dispone que ninguna persona natural o jurídica que no se hubiere constituido conforme a las disposiciones de esta ley como Administradora de Fondos de Pensiones podrá arrogarse la calidad de tal. Tampoco podrá poner en su local u oficina, plancha o aviso que contenga expresiones que indiquen que se trata de una Administradora, ni podrá hacer uso de membretes, carteles, títulos, formularios, recibos, circulares o cualquier otro papel, que contenga nombres u otras palabras que indiquen que los negocios a que se dedican dichas personas son los de Administradora. Y en el artículo 30, agrega: "La razón social de las Administradoras deberá comprender la frase 'Administradora de Fondos de Pensiones' o la sigla 'A.F.P.' y no podrá incluir nombres o siglas de personas naturales o jurídicas existentes, o nombres de fantasía que, a juicio de la Superintendencia de Administradoras de Fondos de Pensiones, puedan inducir a equívocos respecto de la responsabilidad patrimonial o administrativa de ellas".
}

118 Cfr. García (1993), p. 998.

119 Lo anterior no se contrapone, por cierto, al hecho que la autoridad exija que determinadas actividades se desarrollen bajo específicas formas jurídicas preestablecidas, o por el cumplimiento de requisitos adicionales, cuestión que es plenamente coincidente con la libre actividad del empresario. En ese marco se encuadran, por ejemplo, la obligación de constituir sociedades anónimas para los Bancos y Administradoras de Fondos 
Si bien el establecimiento de una actividad productiva, en general, está concebida para participar dentro del ámbito económico, a fin de obtener beneficios al interior de la estructura de mercado, ello no impide que dicha actividad -más allá del cumplimiento de otros resguardos constitucionales- sea creada y organizada sin una estricta finalidad de lucro. Existen, a este respecto, numerosos casos en que el agente organiza una determinada empresa, en las cuales el elemento lucrativo se encuentra limitado o subordinado a otros intereses. Sin ir más lejos, conceptualmente las empresas públicas se constituyen por un objetivo que va más allá de la simple ganancia o utilidad. En consecuencia, la libertad del empresario se traduce en un derecho de organización tanto para actividades lucrativas como no lucrativas ${ }^{120}$.

Por último, señalemos que desde el punto de vista estrictamente laboral, la actividad del empresario se traduce en la práctica, precisamente, en su capacidad de organización, cuestión que le permite gozar de autonomía -dentro del marco legal-para coordinar los elementos que intervienen en el ejercicio de una actividad elaboradora de bienes y servicios ${ }^{121}$. De esta manera, la facultad de organización le otorga al empresario la posibilidad de implementar su propia dirección de recursos humanos, la política de contratación de servicios, la composición o reestructuración de la planta, las decisiones sobre flexibilidad numérica y funcional, los tiempos de trabajo, los planes de seguridad, la política de remuneraciones, o la política de reclamaciones internas, entre otros varios aspectos ${ }^{122}$.

Esa capacidad organizativa, como ya se ha dicho, se encuentra indisolublemente unida a la titularidad civil que le ha reconocido el ordenamiento jurídico, y que trasplantada al ámbito laboral permiten configurar al empleador no sólo como un acreedor de trabajo sino que, también y ante todo, como un titular que puede dirigir tanto las singulares prestaciones de trabajo como la organización

de Pensiones. Asimismo, la Ley No 20.123 exigió que las Empresas de Servicios Transitorios tuviesen la calidad de persona jurídica, inscrita en el registro respectivo. En el plano jurisprudencial vid. sentencia de la Corte de Apelaciones de Santiago, Rol No 102-82, de 29 de abril de 1983: “(...) se trata, en cambio del respeto a las normas legales específicas de una actividad determinada, aquella que la regulan en particular" (considerando $2^{\circ}$ ).

120 Cfr. Cidoncha (2006), p. 258. Vid también Paz-Ares Rodríguez; Alfaro (2008), p. 982, quienes incluso hacen extensivo el derecho a aquellas actividades no habituales.

121 Cfr. por todos Rodríguez-Piñero; Bravo-Ferrer (1960), p. 67. Como señala Montoya (2005), p. 161:

"Si el poder es inherente a toda organización (...), el poder empresarial es consustancial a la organización de la empresa”.

122 Vid. Montoya (2005), pp. 163 y 164. 
general de la empresa ${ }^{123}$. Esta característica de la organización ha servido, en el plano comparado, incluso para acreditar la existencia de un contrato de trabajo. Ese es el caso del Reino Unido, en que la integración del trabajador dentro de la organización del empresario (integration test or organization test), así como la combinación de su trabajo en la actividad de éste, ha sido estimada por la jurisprudencia anglosajona como una presunción suficiente de existencia de la relación laboral. De este modo, se permite diferenciar entre el genérico contrato de arrendamiento de servicios y obras (contract for services) y el específico contrato de trabajo (contract of service) ${ }^{124}$.

\section{LAS FACULTADES DE DIRECCIÓN Y DISCIPLINA EN LA EMPRESA}

De la facultad general de organización de que goza el empresario, surge para éste un poder de dirección y disciplina en el ámbito de la relación de trabajo. Si el empresario se comporta efectivamente como un titular de la organización, el Derecho ha juridificado sus facultades, a objeto de que las diversas atribuciones que ostenta se encuadren dentro de un marco general diseñado por el propio ordenamiento $^{125}$. De allí la importancia que tiene, entre otros, el artículo 19 No 21 CPR como fuente primaria de regulación de los poderes empresariales, pues en definitiva las facultades del empleador se justifican, en parte, en la propia realidad del sistema económico constitucional.

Como es lógico de suponer, toda actividad o comportamiento humano requiere de un conjunto de normas directivas y disciplinarias que aseguren su adecuado funcionamiento. Esto permite que las organizaciones y las entidades creadas por los individuos puedan conseguir los fines que éste se ha trazado de manera normal y regular ${ }^{126}$. Por ello, la idea del poder se refleja, jurídicamente, en la posibilidad de exigir una determinada conducta a otros, lo cual importa, por cierto, la imponibilidad de sanciones al desobediente y la necesaria congruencia entre orden y mandato legal ${ }^{127}$.

123 Vid., Montoya (1965), p. 198. Cfr. también Fernández (2004), pp. 21 y ss.

124 Cfr., entre otros, Drake (1973), pp. 15 y ss.; Galiana (1978), pp. 42 y ss., y Rideout (1976), pp. 4 y 5.

125 Cfr. por todos, Montoya (1965), p. 220. Vid. también, Del Valle (1993), p. 186; Fernández (1996), p. 10, y PÉrez (1987), p. 187.

126 Cfr. por todos, López (1979), pp. 18 y 29, y Montalvo (1985), p. 256.

127 Cfr. Diéguez (1990), p. 334. 
La máxima anterior no escapa a la teoría general del Derecho del Trabajo ${ }^{128}$, ni menos a la empresa específicamente considerada, ya que como toda organización humana requiere de un cierto grado de ordenación y coherencia en la actuación de sus factores, a objeto de alcanzar los fines que ella se ha trazado. Las exigencias organizativas, en consecuencia, dejan al descubierto la necesidad de contar con atribuciones claras que permitan ordenar la prestación de trabajo ${ }^{129}$. Así, la relación laboral nace a la vida del Derecho rodeada de un conjunto de atribuciones y deberes, tanto organizativos como disciplinarios, que ordenan la actividad de las partes dentro de la empresa y le permiten una racionalidad y congruencia en su actividad.

Del principio organizativo que inspira la actuación del empresario -y que se refiere básicamente a la orientación del negocio- se deduce una faceta del poder de disposición patrimonial, que permite al empresario ordenar la vida interna de la organización productiva, exigiendo un determinado nivel de comportamiento en el trabajo ${ }^{130}$. Pero, también, hay que tener en cuenta que por la celebración del contrato de trabajo, el trabajador ingresa en un ámbito regido por un poder de dirección cuyo titular es la persona para la cual trabaja ${ }^{131}$. Lo que ocurre es que, en virtud de la celebración del vínculo laboral, el trabajador procede "a realizar un negocio jurídico doblemente atributivo en favor del empresario: una atribución básica puramente patrimonial y una atribución derivada o instrumental que podemos llamar personal, a saber, la atribución al empresario del poder de ordenar y dirigir la prestación de trabajo"132.

De esta forma, el empresario (ahora en su calidad de empleador) ostenta un conjunto de facultades jurídicas a través de cuyo ejercicio dispone las actividades, ordenando las singulares prestaciones laborales y organizando el trabajo en la empresa. ${ }^{133}$ Este atributo se reflejará en un típico poder de carácter laboral que le permite al empleador adaptar el objeto de la prestación de trabajo a las necesidades

128 Cfr. por todos, Valdés (1993), p. 1.

129 Cfr. por todos, Fernández (1991), pp. 21 y 37; y Rojas (1993), pp. 9 y 10.

130 Cfr. entre otros, BAYON (1959), p. 267; López (1979), p. 24; LYON-CAEN et al. (1994), p. 16, y ROMÁN (1992), p. 77.

131 Sobre las diversas teorías que se han mencionado para explicar la naturaleza de la dirección empresarial, vid. por todos Fernández (1991), pp. 21 y ss.; Montoya (1965), pp. 20 y ss.; Menezes (1994), pp. 659 y ss., y RoMÁn (1992), pp. 113 y ss.

132 Vid. Montoya (1997), p. 28.

133 Cfr. Montoya (1985), p. 132. 
generales de la organización productiva ${ }^{134}$. En consecuencia, el poder de dirección es un poder eminentemente jurídico, innato a la condición del empresario.

En definitiva, este poder se traduce en la capacidad para ejercer un conjunto de facultades de ordenación y organización laboral de la empresa ${ }^{135}$. Y la fundamentación más relevante de ese poder se encuentra precisamente en el reconocimiento constitucional de la libertad económica, la cual termina aplicándose tanto al empresario público como privado. De allí que el poder de dirección deba entenderse como parte integrante del contenido esencial de la libertad de empresa; toda vez que el diseño que la Constitución efectúa del sistema económico y laboral obliga a reconocer en el empresario a un titular dotado de un determinado grado de libertad para gestionar y planificar los factores que intervienen en la organización productiva ${ }^{136}$. Es decir, la conjunción de los derechos económicos, modalizados y en armonía con las prerrogativas del Estado de Derecho, permiten legitimar las atribuciones empresariales a objeto de dirigir y ordenar los diversos factores que participan de la actividad negocial.

El poder de dirección encuentra pleno respaldo, también, en diversas normas del Código del Trabajo. Así, por ejemplo, el artículo $3^{\circ}$, inciso tercero, define a la empresa como una organización de medios "ordenados bajo una dirección"; el artículo $4^{\circ}$, inciso primero, consagra una presunción de derecho en lo que respecta a la representación del empleador (al indicar que representa a éste y que en tal carácter lo obliga con los trabajadores, "la persona que ejerce habitualmente funciones de dirección o administración por cuenta o representación de una persona natural o jurídica"); el artículo $5^{\circ}$, inciso primero, señala que el ejercicio de las facultades que la ley le reconoce al empleador, tiene como límite el respeto a las garantías constitucionales, "en especial cuando pudieran afectar la intimidad, la vida privada o la honra de éstos"; y el inciso cuarto del artículo $8^{\circ}$ del referido texto legal: "No hacen presumir la existencia de contrato de trabajo los servicios prestados en forma habitual en el propio hogar de las personas que los realizan o en un lugar libremente elegido por ellas, sin vigilancia, ni dirección inmediata del que los contrata". Todas estas normas establecen un eje medular del poder directivo como es la facultad de dictar órdenes e instrucciones para configurar las concretas

134 Cfr. entre otros, Cruz (1983), p. 20; Fernández (1991), p. 65, Rojas (1993), p. 9, y Román (1982), pp. 90 y 94 .

135 Cfr. Montoya (1970), p. 417; Montoya (1965), p. 10, y Montoya (1997), p. 28. En igual sentido, cfr., también, RIVERo (1986), pp. 24 y 25.

136 Cfr. Román (1992), pp. 85, 88, 94 y 96. 
obligaciones de los trabajadores que aseguran la buena marcha de la empresa, y permiten la aplicación de sanciones en caso que éstas se incumplan ${ }^{137}$.

Lo anterior permite configurar una noción amplia del poder de dirección, cuestión que trae aparejado el hecho de que el empleador cuente con las herramientas jurídicas necesarias para realizar una gestión eficiente del trabajo ${ }^{138}$. Dentro de este concepto amplio, la facultad de dirección comprende aquellas atribuciones que, sumadas o combinadas, llevan adelante la iniciativa económica del empresario en las relaciones internas de la empresa, atendiendo a los intereses constitucionalmente protegidos de las personas que intervienen en ella. Esta iniciativa supone, además, la capacidad para determinar los niveles de producción y su calidad, la libertad de inversión, de fijación de una política o estrategia comercial, así como la libertad de distribución y venta de productos, e incluso para especificar la prestación de trabajo.

Consecuente con lo anterior, aunque de forma más excepcional, el titular de la actividad productiva, en uso de sus potestades empresariales, podrá modificar los límites de la prestación de servicios, de conformidad con la institución del ius variandi. Existe, como se sabe, un ius variandi ordinario que le permite al empresario disponer libremente, sin alegación de causa y sin límite temporal, los cambios de funciones que estime convenientes dentro de la organización empresarial, aun cuando debe respetar la titulación académica o profesional exigida para el desempeño del puesto de trabajo, así como la pertenencia al grupo profesional ${ }^{139}$. Paralelamente, el empleador ostenta facultades vinculadas a un ius variandi extraordinario, el cual exige para su aplicación que la modificación dure el tiempo imprescindible y que concurran razones técnicas u organizativas que la justifiquen ${ }^{140}$. Excepcionalmente, y por expreso mandato legal, el empresario puede modificar las tareas inherentes al cargo o función en razón de un interés general $^{141}$.

\footnotetext{
137 Vid. Montoya (1970), p. 417.

138 Cfr. Román (1992), pp. 93 y 94. Vid. también, López (1979), pp. 9 y ss.

139 Vid. Montoya (1997), p. 421.

140 Cfr. entre otros el inciso primero del artículo 12 CT, el artículo 29 CT, y el artículo 101 CT.

141 Esa es la hipótesis en que se coloca el inciso primero del artículo 202 del Código del Trabajo: "Durante el período de embarazo, la trabajadora que esté ocupada habitualmente en trabajos considerados por la autoridad como perjudiciales para su salud, deberá ser trasladada, sin reducción de sus remuneraciones, a otro trabajo que no sea perjudicial para su estado".
} 
Cabe agregar, con todo, que puede existir una movilidad de funciones que desborde los supuestos del ius variandi, que se caracteriza en una decisión empresarial cuyo fundamento es un interés también empresarial ${ }^{142}$. Estos casos responden a modificaciones sustanciales de las condiciones de trabajo y tendrán que ser regulados por intermedio de novaciones individuales o colectivas ${ }^{143}$.

En rigor, el ius variandi o la potestad del empresario de alterar unilateralmente los límites de la prestación de servicios sólo se traducirá en modificaciones no sustanciales. Por el contrario, si la modificación adquiere el carácter de esencial, entonces procederá la aplicación de un régimen propio ${ }^{144}$. En lo que respecta a la movilidad geográfica, si ésta no implica un cambio del lugar de trabajo, el ejercicio de esta facultad deberá entenderse incluida dentro del ius variandi del empleador ${ }^{145}$. De verificarse un cambio de residencia, nos encontraríamos en presencia de una modificación sustancial de condición contractual, salvo la hipótesis del artículo 12 del Código ${ }^{146}$.

Este derecho de variación del empleador, que se manifiesta en las facultades de modificación recién expresadas, debe ser ejercido ciñéndose estrictamente a las condiciones que el propio ordenamiento jurídico y el contrato señalan, sin que sea lícito para el acreedor de trabajo disponer de esta atribución en forma antojadiza o incondicionada. Así lo ha entendido la propia jurisprudencia y la doctrina, las cuales han recalcado que el ius variandi-así como los poderes empresariales en general- no puede ser concebido como una facultad arbitraria u omnímoda, sino que se encuentra sometido a determinadas limitaciones, debiendo utilizarse con el máximo respeto a los derechos del trabajador y a su dignidad de persona humana ${ }^{147}$. En todo caso, conviene tener presente que el ordenamiento parte de la base de que el trabajador se encuentra obligado a obedecer la orden o decisión empresarial "que sólo cederá dando paso al jus resistentiae cuando sea patente

142 Vid. Montoya (1997), pp. 420 y 421.

143 Vid., por ejemplo, el inciso final del artículo $5^{\circ}$ del Código del Trabajo: "Los contratos individuales y colectivos de trabajo podrán ser modificados, por mutuo consentimiento, en aquellas materias en que las partes hayan podido convenir libremente".

144 Vid. Montoya (1997), pp. 419 y ss.

145 Vid. por todos Rojas (1993), pp. 21 y ss.

146 Cfr. en esta línea la norma del artículo 53 CT, el cual obliga al empleador a pagar los gastos razonables de ida y vuelta del trabajador "si para prestar servicios lo hizo cambiar de residencia".

147 Cfr., entre otros, López (1979), p. 37; Montoya (1989), p. 169; Pedrajas (1992), p. 39, Pereza (1987), pp. 186 y 187; Rodríguez-Piñero; Bravo-Ferrer (1991), pp. 1072, 1073 y 1084, y Valdés (1993), p. 2. 
lo ilegal o lesivo de la orden y lo irreparable de los daños que derivarían de su cumplimiento" 148 .

Las consideraciones anteriores ponen en evidencia que la fundamentación jurídica del poder empresarial también abarca aquellas potestades que le permiten al empleador adecuarse a la naturaleza dinámica y cambiante de las necesidades organizativas y productivas de la empresa ${ }^{149}$. Una concepción demasiado rígida de estas atribuciones podría llevar a que la específica prestación de trabajo no pudiese adaptarse a los requerimientos concretos que van surgiendo a través de la relación laboral. Por ello, los derechos que surgen del artículo 19 No 21 CPR (y también del 19 No 16 CPR) debieran entenderse insertos dentro de un esquema general de equilibrio entre la seguridad y la movilidad del trabajador ${ }^{150}$.

Es en este contexto, precisamente, donde deben situarse las facultades de variación del empresario: en un reconocimiento general para organizar los factores productivos, en el bien entendido de que esto trae implícito una cierta flexibilidad para adecuar la prestación específica de trabajo ${ }^{151}$. De esta forma, la Constitución reconoce y legitima implícitamente que la organización práctica de las labores sea una atribución exclusiva del empleador, sin perjuicio de que esa atribución tendrá que someterse a una serie de exigencias para evitar un poder omnímodo. En un estadio posterior, serán las normas legales correspondientes, o la autonomía colectiva, las que deberán especificar en mecanismos de diverso orden esta flexibilidad, respetando los derechos básicos que la propia Constitución le reconoce al trabajador.

Por otra parte, y conjuntamente con un poder de dirección, existe para el empresario un atributo disciplinario que obliga a los trabajadores, y los expone a ser sancionados cuando existan incumplimientos laborales o contractuales, de acuerdo con la graduación de las faltas y sanciones que se establezcan en las disposiciones legales, o en el reglamento interno. Dicho poder se refleja, desde el punto de vista del empresario, en un haz de prerrogativas que le permiten preservar su interés en el cumplimiento de las obligaciones derivadas de la relación de trabajo ${ }^{152}, y$ también dar fiel cumplimiento a las exigencias organizativas ${ }^{153}$.

148 Cfr. Montoya (1989), p. 195.

149 Cfr. Montoya (1989), p. 165.

150 Ibidem, p. 166.

151 Cfr. Cruz (1983), pp. 46, 47 y 122. Vid. también, Pérez (1987), p. 190.

152 Esta doble fundamentación no hace más que robustecer la condición acreedora del empleador, pues le permite reaccionar frente a cualquier incumplimiento de su deudor.

153 Cfr. Fernández (1991), pp. 43, 45, 47, 62, 63 y 175. Vid. también, Román (1992), pp. 120 y 121. 
Inmerso en este esquema sancionatorio, el empresario se erige dentro de la relación de trabajo no sólo como un acreedor de éste, sino además, como un sujeto capaz de sancionar la inobservancia laboral del trabajador -incluyendo su faceta contractual- de un modo distinto a como lo hace la normativa civil. Es por esto que, fuera de los incumplimientos generales en que pueda incurrir el dependiente, y que tengan señalada una pena especial por otras ramas del ordenamiento jurídico, el empresario goza de una facultad de sanción para aquellas infracciones que no se compadezcan con un grado mínimo de disciplina en la ejecución de las labores.

A pesar de la desigualdad jurídica que afecta a los contratantes del vínculo laboral, el poder disciplinario no puede ser entendido como una mera supremacía del empresario, ni menos una superioridad absoluta o aplicable a cualquier ámbito de la vida del trabajador; sencillamente, al presentarse aquél como un organizador del trabajo y de las labores dentro de la empresa, se entiende, a este efecto, facultado para imponer directivas, sanciones y correctivos que la ley, el reglamento, o la autonomía colectiva le señalen. Ello viene a explicar el hecho de que el empresario no pueda invadir otros campos ajenos a la relación laboral, como podrían ser aquellos vinculados a la esfera privada del trabajador, más aún si éstos se encuentran reconocidos constitucionalmente ${ }^{154}$. Como aclara la doctrina y jurisprudencia comparada ${ }^{155}$, nadie está obligado a soportar despojos transitorios o limitaciones injustificadas de sus derechos fundamentales y libertades públicas, que tienen un valor central y nuclear en el sistema jurídico constitucional. El trabajador es un ciudadano más, que goza de las mismas garantías que la Constitución le reconoce a los demás individuos que viven en la sociedad, razón por la cual el empresario tendrá que aplicar las medidas de acuerdo a la naturaleza de la falta y sólo circunscrita, en sus efectos, a la prestación de servicios ${ }^{156}$.

El ejercicio del poder de dirección y disciplina, por tanto, debe llevarse a cabo, necesariamente, de forma regular y lógica, sin que pueda admitirse algún grado de discriminación o práctica ilimitada ${ }^{157}$. En cada orden o resolución que

154 Cfr. Montoya (1985), p. 135.

155 Vid. Jiménez-Blanco (1993), p. 506; y DäUbler (1994), p. 615.

156 Hay que tener presente, a este respecto, que la propia Constitución le reconoce a los trabajadores un contrapeso general al poder empresarial como es el derecho a la negociación colectiva entre los representantes de los trabajadores y los empresarios. Vid. en esta línea, y entre otros muchos, Martín (1983), p. 144; DiéGuez (1990), p. 339; Pedrajas (1992), pp. 20, 21, 39 y 41; Rivero (1986), pp. 23 y ss., y Rodríguez-Piñero; Bravo-Ferrer (1996), pp. 12 y ss.

157 Cfr. por todos, López (1979), p. 26. 
tome el empleador tendrá que atenerse obligadamente a lo que preceptúa la ley, el instrumento colectivo, el contrato de trabajo y la propia equidad.

Asimismo, el ejercicio de este poder conlleva la obligación por parte del empresario de actuar en conformidad a la naturaleza de las funciones y deberes exigidos, así como de las faltas, y en directa relación con el carácter laboral de la infracción cometida ${ }^{158}$. Cumplida esa exigencia, el trabajador se entenderá obligado a realizar la prestación conforme a las directrices que señala el empleador. Más aún, la doctrina dominante ha planteado la tesis de la obediencia justa que llega a la conclusión de que en el ámbito de la obediencia laboral la regla general es que las órdenes se presumen lícitas y, por tanto, deben ser obedecidas ${ }^{159}$. No obstante, por excepción, estas órdenes pueden ser ilegítimas y, en consecuencia, no merecedoras de obediencia ${ }^{160}$.

En lo que respecta a las facultades disciplinarias, es preciso recalcar que éstas deben ser ejercidas dentro del ámbito señalado por las normas legales y contratos o convenios colectivos, cuestión que permite estructurar una atribución eminentemente reglada ${ }^{161}$. De lo anterior se deriva el hecho que, en las llamadas sanciones por incumplimiento laboral, exista una graduación de acuerdo a la gravedad de las faltas y sanciones que se establezcan en las disposiciones legales, en el Reglamento Interno, o en el instrumento colectivo que sea aplicable.

En todo caso, conviene tener presente que, al menos en principio, las facultades disciplinarias del empresario obligan eventualmente a excluir del ámbito respectivo una serie de principios propios del ordenamiento penal, como sería el caso, entre otros, de la máxima nullum crimen, nulla poena sine lege ${ }^{162}$. Lo que sucede es que el ejercicio del poder disciplinario requiere, por su especial configuración, de un grado importante de flexibilidad a objeto de optimizar la ordenación de las prestaciones laborales. Si se sostuviera, por el contrario, una concepción demasiado rígida, sería imposible predecir las diversas conductas atentatorias del orden en la empresa descuidándose una serie de imponderables. Todo esto aconseja dejar de lado una aplicación rigurosa del principio de legalidad de las infracciones laborales, de modo que las atribuciones disciplinarias con que cuenta el empleador se puedan ejercer de forma fluida acorde con las circunstancias de cada caso. No

158 Cfr. FernÁNDEZ (1991), p. 105.

159 Vid. Diéguez (1990), p. 334.

160 Vid. Montoya (1985), pp. 138 y 139.

161 Cfr. Fernández (1991), pp. 131 y 141.

162 Cfr. López (1979), p. 29. Vid. también, en relación con el despido disciplinario, Alonso (1958), p. 127. 
obstante, esto no debe ser visto como un medio de autotutela omnímodo que el empresario pueda imponer dejando de lado los límites internos y externos que pesan sobre este tipo de atribuciones ${ }^{163}$.

\section{Derecho a la libre asociación EMPRESARIal}

La libertad de empresa que se consagra en el artículo 19 No 21 CPR supone, también, la atribución de los empresarios para asociarse y conformar organizaciones que los representen ${ }^{164}$. Como se ha dicho doctrinariamente, la asociatividad es un elemento consustancial al ser humano y permite que la persona se vincule con otros para desarrollar sus potencialidades ${ }^{165}$. En el campo de la asociación empresarial, ello admite la formación de mancomunidades para el acceso al mercado, evitando barreras que entorpezcan indebidamente el ejercicio de la libertad empresarial. Este derecho encuentra respaldo, además, en el artículo 19 No 15 de la Constitución, lo cual permite la promoción de las asociaciones empresariales.

En el entramado normativo chileno, las asociaciones empresariales se configuran como interlocutores cualificados en el referido sistema de relaciones laborales, portando para estos efectos un interés colectivo propio que se diferencia de aquel que ostentan sus miembros individuales ${ }^{166}$. Esto lleva a desterrar cualquier estructuración de las asociaciones empresariales como mundos separados y estancos del resto de la sociedad. Por el contrario, estas asociaciones se alzan como interlocutores con identidad propia no sólo del sistema de relaciones laborales, también del sistema económico. Tanto es así, que "las asociaciones empresariales más representativas van a realizar funciones cuyos efectos alcanzan al conjunto de la población empresarial, como la celebración de acuerdos interprofesionales, o la representación de intereses ante las Administraciones públicas"167.

163 Cfr. Fernández (1991), pp. 155 y 156. Y agrega en p. 160: "es que es difícil trasfundir al poder disciplinario, nacido en el seno de un ordenamiento privado, esas mismas reglas y principios sin correcciones, ya que esta vertiente del principio de legalidad tiene un claro alcance político". En sentido contrario, vid. GIL y GIL (1993), p. 37: "De ahí que resulte aplicable, en el ámbito disciplinario, el principio nulla poena sine lege. Defender otra cosa resultaría incoherente con los principios que informan la autotutela privada, la cual posee un carácter excepcional y requiere, en todo caso, una habilitación expresa de la ley; equivaldría a atribuir al empresario un poder genérico e incondicionado, un medio de autotutela ajeno a la más mínima tipicidad: el empresario sería el legislador de sus propios intereses".

164 Cfr. Martínez (1983), p. 669.

165 Vid. Ribera (2007), pp. 282 y 283.

166 Vid. Rey (1983), p. 323.

167 Cfr. GarCía (1987), p. 133. 
A pesar de la existencia de regulaciones simultáneas, y sin perjuicio de que tienen garantizado un ámbito de actuación frente a los poderes públicos ${ }^{168}$, lo cierto es que los sindicatos y las asociaciones empresariales no son figuras equiparables. Sus diferencias se expresan tanto en su evolución histórica, como en su estructura y en los medios de actuación. Pero, sobre todo, su diferenciación se observa en una base sociológica distinta, reflejada en el poder económico que las asociaciones empresariales tienen en el plano de la contratación y en el ámbito de la sociedad ${ }^{169}$.

Al tenor de lo expuesto, las asociaciones empresariales deben ser entendidas como personas jurídicas de carácter privado e interés particular, que gozan de personalidad jurídica propia y plena capacidad de obrar para el cumplimiento de sus fines independientes de la Administración, de las organizaciones de trabajadores y de los poderes públicos ${ }^{170}$

El régimen jurídico de estas organizaciones encuentra su respaldo legal en el Decreto Ley No 2.757, de 4 de julio de 1979. El artículo 10 de dicho cuerpo legal establece que son asociaciones gremiales las "organizaciones constituidas en conformidad a esta ley, que reúnan personas naturales, jurídicas, o ambas, con el objeto de promover la racionalización, desarrollo y protección de las actividades que les son comunes, en razón de su profesión, oficio o rama de la producción o de los servicios, y de las conexas a dichas actividades comunes". Estas asociaciones, agrega el precepto, no podrán desarrollar actividades políticas ni religiosas.

\section{Conclusiones}

1. El artículo 19 No $21 \mathrm{CPR}$, sin definir a la empresa o al empresario, ha trazado sobre la organización productiva las características básicas de funcionamiento de un orden determinado, arrastrando tras de sí una serie de regulaciones de carácter laboral, comercial o tributario. En este sentido, la Constitución regula a la libertad de empresa como un sistema armónico que privilegia la libertad económica con una adecuada y racional intervención del Estado, teniendo como principios fundantes la idea de interés general y orden público económico.

168 Vid. Ojeda (1995), pp. 138 y ss.; Jiménez; Pérez-Ugena (1996), p. 394, y Rivero (1992), p. 15.

169 Desde una perspectiva histórica de las relaciones laborales, las asociaciones de empresarios surgen precisamente a raíz de la aparición del fenómeno sindical; pero ello no debe hacer olvidar que estas organizaciones se caracterizan por perseguir objetivos más amplios que trascienden la esfera laboral, "especialmente por lo que se refiere a los intereses estrictamente económicos”. Vid. REY (1983), pp. 308 y 309.

170 Cfr. Iglesias; Salido (1989), p. 411. 
2. El contenido esencial de la libertad de empresa supone reconocerle a todo individuo no sólo un derecho de acceder al mercado, de competir libremente en él, de organizar la actividad productiva o de cesar en ella, sino que también ha legitimado la creación de nuevas y más complejas formas empresariales. El reconocimiento de estos derechos no es absoluto, y debe armonizarse con un nutrido marco regulatorio cuyo fundamento se encuentra en distintas normas de la Constitución.

3. Dentro del contenido esencial de la libertad de empresa cohabitan un conjunto de derechos de carácter laboral. Y en razón de ello, el artículo 19 No 21 CPR no constituye un precepto aislado de otras normas constitucionales reguladoras del sistema de relaciones laborales. Este sistema sólo puede explicarse de forma adecuada mediante un delicado equilibrio entre el Orden Público Laboral y el Orden Público Económico. Desde esta perspectiva, las principales facultades del empleador en tanto titular de la actividad productiva se explican de manera importante en la norma del artículo 19 No 21 CPR. Los poderes de dirección, organización y disciplina, así como las facultades de contratación, encuentran respaldo en la regulación que la Carta Fundamental ha efectuado de la libertad de empresa. Dicho respaldo permite juridificar los poderes que ostenta el empleador en el ámbito de un contrato de trabajo.

4. Los principales derechos de orden laboral que surgen del artículo 19 No 21 $\mathrm{CPR}$, aunque no los únicos, se vinculan con la libertad de contratación, la libertad de organización y las facultades de dirección y disciplina. En el ejercicio de la libertad de contratación, el empresario goza de un doble derecho. Por una parte, tiene atribuciones para decidir si contrata o no a un trabajador determinado, así como para prorrogar la vigencia de contratos temporales o transformar a éstos en relaciones jurídicas de tiempo indefinido. Y por otra, el empresario se encuentra facultado para elegir libremente a un trabajador concreto, respetando exigencias de idoneidad y no discriminación.

La libertad de organización supone la facultad de ordenar los elementos que intervienen en la empresa, enlazándolos racionalmente y procurando la coordinación de los distintos factores que en ella participan. Dentro de este ámbito, al empresario se le reconocen atribuciones propias que no sólo le permiten elegir la actividad productiva que estime más adecuada a sus intereses, sino que también para crear filiales o darse las formas organizativas -típicas o atípicas- que le permitan alcanzar los fines que tuvo presente al momento de constituir una determinada organización empresarial. Estas atribuciones, trasplantadas al ámbito laboral, configuran al empresario no sólo como un acreedor de trabajo sino que también, 
y ante todo, como un titular que puede dirigir tanto las singulares prestaciones de trabajo como la organización general de la empresa.

De la calidad de titular de una organización, se deriva un poder de dirección a favor del empresario. Estas facultades de dirección permiten ordenar las singulares prestaciones de trabajo y adaptarlas a las necesidades generales de la organización productiva. De allí que el poder de dirección deba entenderse como parte integrante del contenido esencial de la libertad de empresa, toda vez que el diseño que la Constitución efectúa del sistema económico y laboral obliga a reconocer en el empresario a un titular dotado de un determinado grado de libertad para gestionar y planificar los factores que intervienen en la organización productiva. Por cierto, el reconocimiento de la libertad de empresa también acepta la eventual posibilidad de que el empresario fije límites a este poder, ya sea por acuerdo individual o colectivo.

De forma complementaria, el diseño constitucional de la libertad de empresa reconoce que el empresario titular de la organización cuenta con facultades destinadas a sancionar incumplimientos laborales o contractuales, de acuerdo con la graduación de las faltas y sanciones que se establezcan en las disposiciones legales, o en el reglamento interno. Dicho poder se refleja, desde el punto de vista del empresario, en un haz de prerrogativas que le permiten preservar su interés en el cumplimiento de las obligaciones derivadas de la relación de trabajo, y también dar fiel cumplimiento a las exigencias organizativas. Por cierto, este poder no puede ser entendido como una mera supremacía del empresario, ni menos una superioridad absoluta o aplicable a cualquier ámbito de la vida del trabajador. El reconocimiento de la libertad de empresa no permite invadir otros campos ajenos a la relación laboral, como podrían ser aquellos vinculados a la esfera privada del trabajador, más aun si éstos se encuentran reconocidos constitucionalmente. En síntesis, el ejercicio del poder de dirección y disciplina, sólo puede llevarse a cabo de forma regular y lógica, sin que pueda admitirse algún grado de discriminación o práctica ilimitada, ya que el diseño constitucional de la libertad de empresa es incompatible con la arbitrariedad.

\section{Bibliografía CITADA}

\section{Actas Oficiales de la Comisión de Estudios de la Nueva Constitución}

Alberti Rovira, Enoch (1993): "La cláusula de libre circulación y la garantía de la unidad del mercado interno en la Constitución española de 1978", en RCEC (No 14), pp. 35-63. 
Albiol Montesinos, Ignacio (1984): Aspectos laborales de la transmisión de empresas. Madrid, Servicio de Publicaciones Ministerio de Trabajo y Seguridad Social), pp. 129.

Alborch Bataller, Carmen (1980): "Reflexiones en torno a la iniciativa económica privada e iniciativa económica pública en la Constitución española”, en A.A. V.V. Estudios sobre la Constitución española de 1978 (Valencia, Secretariado de Publicaciones Facultad de Derecho Universidad de Valencia), pp. 157-173.

Alemany Zaragoza, Eduardo (1988): "Protección constitucional a los sujetos de relación laboral", en A.A.V.V. Jornadas de Estudios sobre el Titulo Preliminar de la Constitución, Volumen III (Madrid, Dirección General del Servicio Jurídico del Estado, Centro de Publicaciones Ministerio de Justicia), pp. 2103-2126.

Alonso Olea, Manuel (1958): El despido (Madrid, Instituto de Estudios Políticos), pp. 261.

Álvarez Conde, Enrique (1992): Curso de Derecho Constitucional, Vol. I (Madrid, Editorial Tecnos), pp. 444.

Aragón ReYes, Manuel (2005): "El contenido esencial del derecho constitucional a la libertad de empresa", en Libertad de empresa y relaciones laborales en España (dirección de Francisco Pérez de los Cobos Orihuel, Madrid, Instituto de Estudios Económicos), pp. 23-56.

Ariño Ortiz, Gaspar (1995): Principios constitucionales de la libertad de empresa. Libertad de comercio e intervencionismo administrativo (Madrid, Marcial Pons e Instituto de Estudios de Libre Comercio), pp. 133.

Balado Ruiz-Gallegos, Manuel (1994): "Notas sobre el modelo económico constitucional español”, en A.A.V.V. El sistema Económico en la Constitución Española, Volumen I (Madrid, Dirección General del Servicio Jurídico del Estado, Centro de Publicaciones Ministerio de Justicia), pp. 31-70.

BARNes VÁZQUeZ, Javier (1988): La propiedad constitucional. El estatuto jurídico del suelo agrario (Madrid, Editorial Civitas), pp. 624.

Bassa Mercado, Jaime, y Viera Álvarez, Christian (2012), "Un nuevo giro hermenéutico de la Corte Suprema en la aplicación del recurso de amparo económico", en RDDPUCV (XXXVIII 1er. Sem.), pp. 661-683.

Bassols Coma, Martín (1988): Constitución y sistema económico (Madrid, Editorial Tecnos, 2a edición), pp. 345.

BAYON CHACÓN, Gaspar (1959): "El concepto jurídico-laboral de empresa”, en RFDUM No 6, pp. 249-292.

Benda, Ernst, Mainofer, Werner, Vogel, Hans-Jochen, Hesse, Konrad y HeYDE, Wolfgang (1996): Manual de Derecho Constitucional (edición y traducc. 
Antonio López Pina. Madrid, Instituto Vasco de Administración Pública y Editorial Marcial Pons), pp. 906.

Bertelsen Repetto, Raúl (1987): "El Estado empresario en la Constitución de 1980", en RCHD (Vol. 14 No 1), pp. 115-125.

Cea Egaña, José Luis (1991): "Notas sobre Orden Público Económico", en GJ (No 135), pp.18-32.

Cea Egaña, José Luis (2004): Derecho constitucional chileno (Santiago, Ediciones Universidad Católica de Chile), Tomo II, pp. 733.

Cidoncha, Antonio (2006): La libertad de empresa (Madrid, Editorial Civitas), pp. 412.

Conde Martín de Hijas, Vicente (1996): "Libertad empresarial y principio de igualdad en el ejercicio de las facultades disciplinarias en la empresa”, en AL (No 1), pp. 95-144.

Crisafulli, Vezio y Paladín, Livio (1990): Commentario breve alla Constituzione (Padova, Cedam-Casa Editrice Dott), pp. 854.

Cruz Villalón, Jesús (1983): Las modificaciones de la prestación de trabajo (Madrid, Servicio de Publicaciones Ministerio de Trabajo y Seguridad Social), pp. 462.

Cruz Villalón, Pedro (1992): "Dos cuestiones de titularidad de derechos fundamentales: los extranjeros; las personas jurídicas”, en REDC (Año 12, No 35), pp. 63-84.

DÄUbler, Wolfgang (1994): Derecho del Trabajo (Traducc. ACERo, Pío y acero, María Paz, Madrid, Centro de Publicaciones Ministerio de Trabajo y Seguridad Social), pp. 1021.

De Gispert Pastor, María Teresa: (1989): "La noción de empresa en la Constitución española”, en A.A.V.V. La Empresa en la Constitución Española (Pamplona, Editorial Aranzadi), pp. 37-64.

De Juan Asenjo, Óscar (1984): La Constitución Económica Española (Madrid, Centro de Estudios Constitucionales), pp. 371.

De los Mozos, José Luis (1993): El derecho de propiedad: crisis y retorno a la tradición jurídica (Madrid, Edersa), pp. 333.

De Otto y Pardo, Ignacio (1992): 'La regulación del ejercicio de los derechos y libertades. La garantía de su contenido esencial en el artículo 53.1 de la Constitución", en A.A.V.V. Derechos Fundamentales y Constitución (Madrid, Editorial Civitas, reimpresión), pp. 95-170. 
Del Rey Guanter, Salvador (1983): "Las asociaciones empresariales en el sistema de relaciones laborales: una aproximación inicial", en RPS (No 137), pp. 301-346.

Del Valle Villar, José Manuel (1993): "Los límites a los poderes del empresario en el Estado de Derecho", en La Reforma del Mercado de Trabajo (dirección de Efrén Borrajo Dacruz, Madrid, Actualidad Editorial), pp. 184-201.

Diéguez Cuervo, Gonzalo (1990): "Poder empresarial: Fundamento, contenido y límites", en A.A.V.V. Temas de Direito do Trabalho, IV Jornadas Luso-Hispano-Brasileiras de Direito do Trabalho (Coimbra, Coimbra Editora), pp. 333-343.

Donges, Juergen B. (1977): "Sistema Económico y Constitución Alemana", en Constitución y Economía. La ordenación del sistema económico en las Constituciones occidentales (coordinación de Luis Sánchez Agesta, Madrid, Centro de Estudios y Comunicación Económica, Publicaciones de Revista de Derecho Público), pp. 129-142.

Dougnac Rodríguez, Fernando (1986): "La garantía constitucional del No 21 del artículo 19 de la Constitución en relación con las demás que configuran el 'Orden Público Económico'”, en GJ (No 68), pp. 6-12.

Drake, Charles D. (1973): Labour Law (London, Sweet and Maxwell Limited, 2a edición), pp. 358.

Fermandois VöHringer, Arturo (2001), Derecho constitucional económico (Santiago, Ediciones Universidad Católica de Chile), Tomo I, pp. 252.

FERnÁNDEZ farreres, Germán (1991): "Industria”, en Derecho Administrativo Económico (dirección de Sebastián Martín-Retortillo, Madrid, Editorial La Ley), Tomo II, pp. 407-554.

FERNÁNDEZ López, María Fernanda (2004): "El empresario como parte del contrato de trabajo: una aproximación preliminar", en Empresario, contrato de trabajo y cooperación entre empresas (coordinación de María Fernanda Fernández López, Madrid, Editorial Trotta), pp. 21-92.

Fernández López, María Fernanda (1996): “Perfiles del poder disciplinario”, en TS (No 63), pp. 10-16.

FERnÁNDEZ López, María Fernanda (1991): El poder disciplinario en la empresa (Madrid, Editorial Civitas), pp. 459.

FERnÁNdeZ-Novoa Rodríguez, Carlos (1965): "Reflexiones preliminares sobre la empresa y sus problemas jurídicos”, en RDM (Vol. XXXIX No 95), pp. 7-40. 
Fernández Villazón, Luis Antonio (1994): “Tratamiento automatizado de datos personales en los procesos de selección de trabajadores”, en RL (No I), pp. 510-538.

Font Galán, Juan Ignacio (1979): "Notas sobre el modelo económico de la Constitución española de 1978”, en RDM (No 152), pp. 205-239.

Font Galán, Juan Ignacio (1987): Constitución económica y derecho de la competencia (Madrid, Editorial Tecnos), pp. 350.

Freixes Sanjuan, Teresa (1988): "El contenido esencial de los derechos fundamentales a través de los límites o en una formulación positiva. Análisis a partir del artículo 20 C.E”., en Introducción a los Derechos Fundamentales, Vol. I (Madrid, Centro de Publicaciones Ministerio de Justicia), pp. 505-541.

Galiana Moreno, Jesús María (1978): El contrato de trabajo en el Derecho inglés (Barcelona, Editorial Bosch), pp. 302.

Gallego Anabitarte, Alfredo (1994): Derechos fundamentales y garantías institucionales: análisis doctrinal y jurisprudencial (Madrid, Editorial Civitas), pp. 303.

GarCÍA de EnTERría, Eduardo (1985): La Constitución como norma y el Tribunal Constitucional (Madrid, Editorial Civitas, $3^{\text {a }}$ edición), pp. 264.

García Fernández, Manuel (1993): "Libertad empresarial de organización y exigencias del principio de igualdad", en La Reforma del Mercado de Trabajo (dirección de Efrén Borrajo Dacruz, Actualidad Editorial), pp. 997-1026.

GarCía Murcia, Joaquín (1987): Organizaciones sindicales y empresariales más representativas (Madrid, Centro de Publicaciones Ministerio de Trabajo y Seguridad Social), pp. 267.

García-Pelayo, Manuel (1979): "Consideraciones sobre las cláusulas económicas de la Constitución”, en Estudios sobre la Constitución española de 1978 (Edición preparada por Manuel Ramírez, Zaragoza, Libros Pórticos), pp. 29-53.

García Vitoria, Ignacio (2008): La libertad de empresa: ¿un terrible derecho? (Madrid, Centro de Estudios Políticos y Constitucionales), pp. 324.

GIL y GIL, José Luis (1993): Autotutela privada y poder disciplinario en la empresa (Madrid, Centro de Publicaciones del Ministerio de Justicia), pp. 178.

Girón Tena, José (1985-1986): Apuntes de Derecho Mercantil. La Empresa (Madrid, Ediciones Facultad de Derecho Universidad Complutense), Tomo I, pp. 164.

Goig Martínez, Juan Manuel (1996): “Artículo 38. La libertad de empresa”, en Comentarios a la Constitución española de 1978 (dirección de Óscar Alzaga Villamil, Madrid, Edersa), Tomo III, pp. 731-745. 
GonZÁlez Biedma, Eduardo (1989): El cambio de titularidad de la empresa en el Derecho del Trabajo (Madrid, Centro de Publicaciones Ministerio del Trabajo y Seguridad Social), pp. 362.

González Iturra, Marco Antonio (2007): Competencia desleal. Análisis crítico y elementos para la aplicación de la Ley No 20.169, de 2007, en CEJ (No 14), pp. 134.

Guerrero, Roberto (1979): "La Constitución económica", en RCHD (Vol. 6), pp. 79-94.

Guerrín, Maurice y Krriazis, Georgios (1994): "Carteles: Aspectos procesales y probatorios”, en RJCEE (serie D-21), pp. 271-366.

Iglesias Berenguer, Rodrigo y SAlido Banus, José Luis (1989): “El asociacionismo empresarial", en A.A.V.V. La empresa en la Constitución española (Pamplona, Editorial Aranzadi), pp. 409-438.

Irarrázaval Covarrubias, Arturo (1987), "Principios económicos de la Constitución de 1980”, en RCHD (Vol. 14), pp. 97-112.

Irureta Uriarte, Pedro (2000): "La libertad de empresa: un caso de derecho comparado”, en Persona y Sociedad (Vol. XIV No 3), pp. 99-118.

IrUReta Uriarte, Pedro (2006): Constitución y orden público laboral: Un análisis del art. 19 No 16 de la Constitución chilena (Santiago, Colección de Investigaciones Jurídicas No 9, Universidad Alberto Hurtado), pp. 234.

Irureta Uriarte, Pedro (2008): "Estadios previos al contrato de trabajo: tratos preliminares y precontrato", en EL (No 2), pp. 47-65.

JimÉnez-Blanco, Antonio (1993): Comentario a la Constitución. La jurisprudencia del Tribunal Constitucional (Madrid, Editorial Centro de Estudios Ramón Areces), pp. 926.

Jiménez de Parga, Manuel y Pérez-Ugena Oromina, María (1996): "Sindicatos", en Comentarios a la Constitución española de 1978 (dirección de Óscar Alzaga Villamil, Madrid, Edersa), Tomo I, pp. 391-408.

López, Justo (1979): “La facultad de dirección”, en RPS (No 122), pp. 9-46.

Lorenzo Rodríguez-Armas, Magdalena (1996): Análisis del contenido esencial de los derechos fundamentales enunciados en el artículo 53.1 de la Constitución española (Granada, Editorial Comares), pp. 252.

Lyon-Caen, Gérard, Pélissier, Jean y Supiot, Alain (1994): Droit du Travail (Paris, Editorial Dalloz, 17a edition), pp. 919. 
MANRique López, Fernando (1994): 'Las relaciones laborales en los países miembros de la CEE”, en BEE (No 151 Vol. XLIX), pp. 23-68.

Martín Valverde, Antonio (1981): "Sistema económico y agricultura en la Constitución española”, en AS (No 21), pp. 9-59.

MarTín VALVERDE, Antonio (1983): "El ordenamiento laboral en la jurisprudencia del Tribunal Constitucional”, en RPS (No 137), pp. 105-168.

Martín-Retortillo Baquer, Sebastián (1988): Derecho Administrativo Económico (Madrid, Editorial La Ley), Tomo I, pp. 504.

Martínez Rocamora, Luis G. (1988): Decisiones empresariales y principio de igualdad (Barcelona, Editorial Cedes), pp. 357.

Martínez Val, José María (1985): "El contenido esencial de la libertad de empresa”, en RGD (Núms. 493-94), pp. 3167-3194.

Martínez Val, José María (1983): "Libertad de empresa", en Comentarios a las Leyes Políticas. Constitución Española de 1978 (dirección de Óscar Alzaga Villaamil, Madrid, Edersa), Tomo III, pp. 647-670.

Menezes Cordeiro, António (1994): Manual de Dereito do Trabalho (Coimbra, Livraria Almedina, reimpresión), pp. 895.

Menéndez Menéndez, Aurelio (1985): "Constitución, sistema económico y derecho mercantil”, en HP (No 94), pp. 47-77.

Miñambres Puig, César (1985): El Centro de Trabajo (Madrid, Servicio de Publicaciones Ministerio de Trabajo y Seguridad Social), pp. 251.

Miranda, Jorge (1993): Manual de Direito Constitucional (Coimbra, Coimbra Editora, 2a edición), Tomo IV, pp. 485.

Montalvo Correa, Jaime (1985): "Modelo económico y social de la Constitución y relaciones laborales", en AA.VV. Jornadas sobre Derecho del Trabajo y Constitución (Madrid, Instituto de Estudios Laborales y de la Seguridad Social, Servicio de Publicaciones Ministerio de Trabajo y Seguridad Social), pp. 235-257.

Montoya MarTín, Encarnación (1995): Las empresas públicas sometidas al Derecho privado. (Madrid, Marcial Pons Ediciones), pp. 662.

Montoya Melgar, Alfredo (2008): Derecho del Trabajo (Madrid, Editorial Tecnos, $29^{a}$ edición), pp. 827.

Montoya Melgar, Alfredo (2005): "Libertad de empresa y poder de dirección del empresario", en Libertad de Empresa y Relaciones Laborales en España (dirección de Francisco Pérez de los Cobos Orihuel, Madrid, Instituto de Estudios Económicos), pp. 131-180. 
Montoya Melgar, Alfredo (1997): Derecho y Trabajo (Madrid, Editorial Civitas), pp. 116.

Montoya Melgar, Alfredo (1994): “Sobre empresa y política”, en REDT (No 64), pp. 197-206.

Montoya Melgar, Alfredo (1989): "Poder del empresario y movilidad laboral", en REDT (No 38), pp. 165-190.

Montoya Melgar, Alfredo (1985): "Dirección de la Actividad Laboral”, en Comentarios a las Leyes Laborales. El Estatuto de los Trabajadores (dirección de Efrén Borrajo Dacruz, Madrid, Edersa), Tomo V, pp. 101-152.

Montoya Melgar, Alfredo (1980): “La protección constitucional de los derechos laborales", en A.A.V.V. Derecho del Trabajo y de la Seguridad Social en la Constitución (Madrid, Centro de Estudios Constitucionales), pp. 269-299.

Montoya Melgar, Alfredo (1970), "La empresa y el Derecho del Trabajo", en A.A.V.V. Tercer Congreso Iberoamericano de Derecho del Trabajo, Sevilla 1970 (Madrid, Servicio de Publicaciones Ministerio del Trabajo), pp. 389-440.

Montoya Melgar, Alfredo (1965): El poder de dirección (Madrid, Instituto de Estudios Políticos), pp. 289.

Navarro Beltrán, Enrique (1998): "Protección y amparo de la libertad económica en Chile e Hispanoamérica", en RCHD (Vol. 25 № 1), pp. 185-195.

NAVARro Beltrán, Enrique (2001): "La libertad económica y su protección”, en RCHD (Vol. 28 No 2), pp. 299-310.

Nogueira Alcalá, Humberto (1997): Dogmática Constitucional (Santiago, Editorial Universidad de Talca), pp. 380.

Nogueira Alcalá, Humberto (2005): "Aspectos de una Teoría de los Derechos Fundamentales: La Delimitación, Regulación, Garantías y Limitaciones de los Derechos Fundamentales", en Ius et Praxis (No 11), pp. 15-64.

Ojeda Avilés, Antonio (1995): Derecho Sindical (Madrid, Editorial Tecnos, $7^{\mathrm{a}}$ edición), pp. 840.

Ossenbuhl, Fritz (1991): "Las libertades del empresario según la Ley Fundamental de Bonn”, en REDC (Año XI, Núm. 32), pp. 9-44.

Palomeque López, Manuel-Carlos (1989): Despidos discriminatorios y libertad sindical (Madrid, Editorial Civitas), pp. 174.

Paz-Ares Rodríguez, Cándido y Alfaro Águila-Real, Jesús (2008): "Artículo 38”, en Comentarios a la Constitución española (dirección de María Emilia Casas Baamonde y Miguel Rodríguez-Piñero y Bravo-Ferrer, Madrid, Fundación Wolters Kluwer), pp. 980-1000. 
Pedrajas Moreno, Abdón (1992): Despido y derechos fundamentales (Madrid, Editorial Trotta), pp. 400.

Pérez del Río, María Teresa (1987): 'La 'regularidad del ejercicio del Poder empresarial y la obediencia debida'”, en PJ (No 6), pp. 183-206.

Pérez Luño, Antonio Enrique (1983): 'Propiedad privada y herencia", en Comentarios a las Leyes Politicas. Constitución española de 1978 (dirección de Óscar Alzaga Villamil, Madrid, Edersa), Tomo III, pp. 382-431.

Prieto Sanchís, Luis (1984a): "Protección de los derechos fundamentales", en Comentarios a las Leyes Políticas (dirección de Óscar Alzaga Villamil, Madrid, Edersa), Tomo IV, pp. 449-495.

Prieto Sanchís, Luis (1984b): "Garantías de las libertades y derechos fundamentales", en Comentarios a las Leyes Politicas (dirección de Óscar Alzaga Villamil, Madrid, Edersa), Tomo IV, pp. 435-445.

Rey MartíneZ, Fernando (1994): La propiedad privada en la Constitución española (Madrid, Boletín Oficial del Estado y Centro de Estudios Constitucionales), pp. 462.

Ribera Neumann, Teodoro (2007): "La protección constitucional de la empresa: La individualidad determinada y la teoría del levantamiento del velo", en Sentencias destacadas 2006 (edición de Arturo Fermandois Vöhringer, Santiago, Instituto Libertad y Desarrollo), pp. 275-298.

Rideout, Roger W. (1979): Principles of Labour Law (Londres, Sweet and Maxwell, $2^{\text {a }}$ edición), pp. 464.

Rivas Vaño, Alicia y Rodríguez-Piñero y Bravo-Ferrer, Miguel (2006): "Relaciones laborales y libertad de empresa: algunas reflexiones", en A.A.V.V. Las transformaciones del Derecho del Trabajo en el marco de la Constitución española. Estudios en homenaje al profesor Miguel Rodriguez-Piñero y Bravo-Ferrer (coordinación de María Emilia Casas Baamonde, Federico Durán López y Jesús Cruz Villalón, Madrid, La Ley), pp. 745-778.

Rivero Lamas, Juan (1986): Limitación de los poderes empresariales y democracia industrial (Zaragoza, Secretariado de Publicaciones, Universidad de Zaragoza), pp. 144.

Rivero Lamas, Juan (1992): "La legitimación empresarial para la negociación colectiva”, en RL (No 24), pp. 414-460.

Rodríguez-Piñero y Bravo-Ferrer, Miguel (1960): "Empresa y contrato de trabajo", en AUH (Año XXI, No II), pp. 41-84. 
Rodríguez-Piñero y Bravo-Ferrer, Miguel (1983): "No discriminación en las relaciones laborales", en Comentarios a las Leyes Laborales. El Estatuto de los Trabajadores (dirección de Efrén Borrajo Dacruz, Madrid, Edersa), Tomo IV, pp. 325-452.

Rodríguez-Piñero y Bravo-Ferrer, Miguel (1991): "Principio de igualdad y Derecho del Trabajo", en A.A.V.V. El Principio de Igualdad en la Constitución Española (Madrid, Centro de Publicaciones Ministerio de Justicia), Volumen II, pp. 1067-1102.

RodríGuez-Piñero y Bravo-Ferrer, Miguel (1996): "Constitución, derechos fundamentales y contrato de trabajo”, en RL (Año 12 No 1/2), pp. 107-116.

Rodríguez-Piñero y Bravo-Ferrer, Miguel (2003): "Poderes empresariales y autonomía contractual”, en A.A.V.V. Estudios jurídicos en homenaje al profesor Luis Diez-Picazo (Madrid, Thomson-Civitas), Tomo IV, pp. 6059-6086.

Rojas Rivero, Gloria P. (1993): Traslado y desplazamiento de trabajadores (Madrid, Centro de Publicaciones Ministerio de Trabajo y Seguridad Social), pp. 148.

Román de la Torre, María Dolores (1992): Poder de Dirección y Contrato de Trabajo (Valladolid, Ediciones Grapheus), pp. 461.

Rubio Llorente, Francisco (1996): "La libertad de empresa en la Constitución”, en Estudios jurídicos en homenaje al profesor Aurelio Menéndez (dirección de Juan Luis Iglesias Prada, Madrid, Editorial Civitas), pp. 431-446.

Sala Franco, Tomás (1995), director, Derecho del Trabajo (Valencia, Editorial Tirant Lo Blanch, 9a edición), pp. 782.

SánChez Blanco, Ángel (1992): El sistema económico de la Constitución española (Madrid, Editorial Civitas), pp. 581.

Serrano Carvajal, José (1979): "Libertad de empresa en la Constitución española”, en RPS (No 121), pp. 439-468.

Tornos Mas, Joaquín (1991): “Ordenación Constitucional del Comercio", en Estudios sobre la Constitución Española, Homenaje al profesor Eduardo García de Enterría (coord. Sebastián Martín Retortillo, Madrid, Editorial Civitas), Tomo V, pp. 4105-4136.

Torres del Moral, Antonio (1992): Principios de Derecho Constitucional Español (Madrid, Servicio de Publicaciones de la Facultad de Derecho, Universidad Complutense, $3^{\text {a }}$ edición renovada), Tomo I, pp. 660.

VAldés DAL-RÉ, Fernando (1990): "Poderes del empresario y derechos de la persona del trabajador”, en RL (No 1), pp. 277-294. 
VAldés DAL-RÉ, Fernando (1993): "Poder directivo, contrato de trabajo y ordenamiento laboral”, en RL (No 5), pp. 26-32.

Vivanco MarTínez, Ángela (2006): Curso de Derecho Constitucional (Santiago, Ediciones Universidad Católica de Chile), Tomo II, pp. 555.

Zamora Cавот, Francisco Javier (1986): "Algunas claves del Derecho Antitrust de los Estados Unidos”, en RDM (No 181-182), pp. 367-422.

\section{Jurisprudencia citada}

Fiscal Nacional Económico contra Laboratorio Recalcine S.A. (1986): CORTE SUPREMA de 13 de mayo de 1986 (requerimiento) en: RDJ Tomo LXXXIII (1986), sección sexta, pp. 55-63.

G.F.O y M.B.S. con Alcalde de la Municipalidad de Santiago (1983): CORTE DE Apelaciones de Santiago de 29 de abril de 1983 (Recurso de Protección), en: GJ No 35 (1983), pp. 65-69.

Administradora de Inversiones y Supermercados Unimarc S.A. con Inspección Provincial del Trabajo Santiago-Norte (1991): CorTe Suprema de 9 de julio de 1991 (recurso de protección), en: RDJ Tomo LXXXVIII, sección quinta, pp. 201-205.

Administradora de Inversiones y Supermercados Unimarc S.A. con Inspección Comunal del Trabajo Cordillera (1991): CORTE Suprema de 23 de octubre de 1991 (recurso de protección), en: RFM No 396, pp. 703-707.

Comercial e Inmobiliaria Unimarc S.A. con Inspección Comunal del Trabajo Santiago-Sur (1991): CoRTE Suprema de 5 de diciembre de 1991 (Recurso de Protección), en: RDJ, T. LXXXVIII, sección quinta, pp. 302-307.

Requerimiento formulado por diversos diputados para que el Tribunal declare la inconstitucionalidad del Decreto Supremo No 327, del Ministerio de Obras Públicas, publicado en el Diario Oficial de 29 de diciembre de 1992 (1993). Tribunal Constitucional 6 de abril de 1993 (requerimiento para que se declare inconstitucional decreto supremo), Rol No 167-1993, en www.tribunalconstitucional.cl

Control de constitucionalidad respecto del proyecto de ley sobre Bases del Medio Ambiente (1994). Tribunal Constitucional de 28 de febrero de 1994 (control de constitucionalidad de proyecto de ley, Rol No 185-1994), en www.tribunalconstitucional.cl 